\title{
Design of a Two-Phase Buck Converter With Fourth-Order Output Filter for Envelope Amplifiers of Limited Bandwidth
}

Javier Sebastián

\author{
Pablo Fernández-Miaja. \\ Moisés Patiño and Miguel Rodríguez
}

Francisco Javier Ortega-González

\begin{abstract}
The use of techniques such as envelope tracking (ET) and envelope elimination and restoration (EER) can improve the efficiency of radio frequency power amplifiers (RFPA). In both cases, high-bandwidth DC/DC converters called envelope amplifiers (EA) are used to modulate the supply voltage of the RFPA. This paper addresses the analysis and design of a modified two-phase Buck converter optimized to operate as EA. The effects of multiphase operation on the tracking capabilities are analyzed. The use of a fourth-order output filter is proposed to increase the attenuation of the harmonics generated by the PWM operation, thus allowing a reduction of the ratio between the switching frequency and the converter bandwidth. The design of the output filter is addressed considering envelope tracking accuracy and distortion caused by the side bands arising from the nonlinear modulation process. Finally, the proposed analysis and design methods are supported by simulation results, as well as demonstrated by experiments obtained using two 100-W, 10-MHz, two-phase Buck EAs capable of accurately tracking a 1.5-MHz bandwidth OFDM signal.
\end{abstract}

Index Terms-DC-DC power converters, harmonic filters, power conversion harmonics, pulse width modulation converters, radiofrequency amplifiers.

\section{INTRODUCTION}

$\mathbf{T}$ HE use of envelope tracking (ET) techniques is an attractive option to increase the efficiency of linear power amplifiers (LPAs) [1]-[20]. The maximum theoretical efficiency of an LPA depends on the relationship between the peak value of the signal at the output of the amplifier and its supply voltage. For instance, it is well known that the maximum efficiency of

This work was supported by the Spanish Ministry of Education and Science under Consolider Project RUE CSD2009-00046 and Project DPI2010-21110-C02-0, and the European Regional Development Fund (ERDF) Grants.

J. Sebastián and P. Fernández-Miaja are with the Grupo de Sistemas Electrónicos de Alimentación (SEA). Campus Universitario de Viesques. Universidad de Oviedo, 33204 Gijón. SPAIN (e-mail: sebas@uniovi.es; fernandezmiapablo@uniovi.es).

F. J. Ortega González and M. Patiño are with the Radio Engineering Group (GIRA), Universidad Politécnica de Madrid, 28006 Madrid, Spain (e-mail: fjortega@diac.upm.es; mopatigo@hotmail.com).

M. Rodríguez is with the Department of Electrical and Computer Engineering, University of Colorado at Boulder, Boulder, CO 80309 USA (e-mail: miguel.rodriguez@colorado.edu).

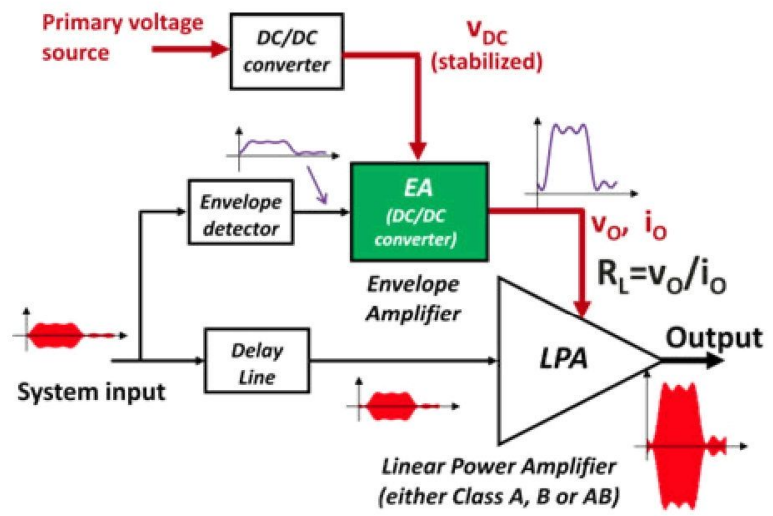

Fig. 1. General scheme for a power amplifier system using the ET technique to improve the overall system efficiency.

an ideal Class-B amplifier is $\pi / 4$ (i.e., $78.5 \%$ ), which occurs when the amplifier operates at maximum power (maximum peak output voltage). This efficiency sharply decreases when the amplifier operates below its maximum power (lower peak output voltages), which happens very often when the signals are amplitude-modulated. This problem becomes especially acute when the signals also have a high peak-to-average ratio, which is common in current radio frequency (RF) applications, where the use of modern communication standards, such as orthogonal frequency-division multiplexing (OFDM), enhanced data rates for GSM evolution (EDGE), wideband code-division multiple access (WCDMA), etc., is widespread. However, the same problem can be found in other power electronics applications [21], [22].

To alleviate this problem, the ET technique varies the supply voltage of the LPA $v_{O}$ (see Fig. 1) according to the peak values of the signal that is being amplified in order to maintain the LPA operating as close as possible to the maximum theoretical limit. The supply voltage has to be varied by a dc/dc converter able to track the envelope of the signal being transmitted (see Fig. 1). In order to obtain high overall system efficiency, a switching mode de/dc converter must be used. A switching converter used for envelope tracking is typically called an envelope amplifier (EA). A variety of switching-mode de/de converters have been proposed to be used as an EA [1]-[20], sometimes with the help of a linear stage to increase the overall bandwidth [13]-[18]. Those derived from the basic Buck converter [1], [3], [5], [6], [8]-[12], [14]-[16], [18] are especially suitable for this application because they have a linear relationship between 
the duty cycle and the output voltage, when they operate in the continuous conduction mode (CCM) [23].

Different techniques used to increase the efficiency of RFPAs, such as envelope elimination and restoration (EER) [24]-[31], also need the use of a dc/dc converter working as an EA, in this case with even better performances than those required for ET. The general scheme of a transmitter that uses the EER technique is very similar to the one shown in Fig. 1, the main difference being that a switching-mode power amplifier (SMPA) is used instead of an LPA. An EA that tracks the envelope of the signal being amplified is also required, and thus the considerations stated in this study are also applicable to EER systems.

As mentioned earlier, EAs have to vary their output voltage very fast to track the waveform being amplified. The input voltage of these dc/dc converters $v_{\mathrm{DC}}$ (see Fig. 1) is maintained constant by a standard dc/dc converter and the equivalent load that either the LPA or the SMPA represent for the EA has an almost constant value $R_{L}$. To achieve the fastest output voltage variation, one possibility is to operate the EA in an open loop. Buck converters are especially suitable for this approach due to the linear relationship that exists between the duty cycle and the output voltage at a constant input voltage if the converter is operating in the CCM. It should be noted that the use of a feedback loop, either of the EA output voltage [1]-[5], [8], [11], [29], [30], or of the RF envelope [6], [25], [28], guarantees a linear relationship between the control signal and the output voltage, even if the converters operates in the discontinuous conduction mode (DCM) or if the load is no longer constant. However, in this case the overall bandwidth is limited not only by the reactive elements of the power stage, but also by the dynamic response of the error amplifier, additional delays in the feedback loop, etc.

Note that the design of the output filter for a Buck EA implies a tradeoff between its cut-off frequency $f_{c}$ and the converter switching frequency $f_{s}$; for a given application, $f_{c}$ is mainly determined by the admissible distortion on the envelope signal. The tradeoff arises because a high switching frequency is desirable to enable the filter to eliminate the switching frequency (and intermodulation products around it), but that compromises the efficiency of the EA. To minimize the ratio between $f_{s}$ and $f_{c}$ to maximize efficiency for a given value of $f_{c}$, the order of the converter output filter can be increased from second to fourth [11], [32], [33] [see Fig. 2(a)] or to sixth. The use of a high-order filter hardens the design of a feedback loop [32] and, therefore, operation in an open loop is recommended. In this study, the linearity between the duty cycle and the output voltage is guaranteed by the operation in CCM.

Another possibility to minimize the ratio between $f_{s}$ and $f_{c}$ is to use a multiphase Buck EA [5] , [8] [see Fig. 2(b)]. In this case, the current injected into the output $\mathrm{RC}$ cell has lower current ripple due to the phase-shifted operation.

The use of high-order filters and multiphase operation, with particular focus on two-phase operation, is addressed in this paper, which is organized in the following manner: the topological alternatives for this type of converters and the calculations to obtain a transfer function for the equivalent output filter will be presented in Section II. Moreover, the behavior of different

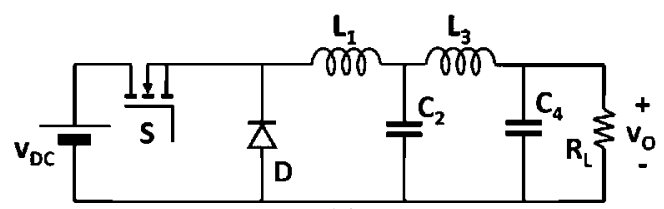

(a)

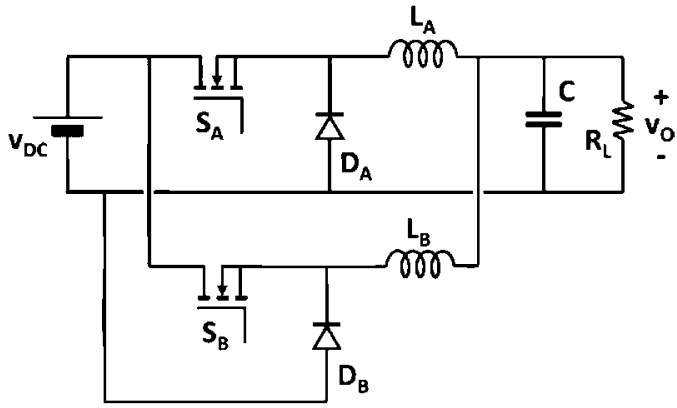

(b)

Fig. 2. (a) Buck converter with a fourth-order output filter. (b) Two-phase Buck converter.

types of filters will be compared in this section. The design of the most appropriate type of filter for reproducing band-limited envelopes will be studied in Section III. In Section IV, the implementation of this type of filter will be addressed. The simulation and experimental results will be shown in Section V. Finally, the conclusions will be presented in Section VI.

\section{Multiphase Buck Converters With High-ORder OUTPUT FILTER}

The use of multiphase Buck converters as envelope amplifiers (EA) is motivated by its advantages over its single-phase counterpart; for instance, it provides lower output voltage ripple and allows power sharing between the phases. In [33], a detailed study of the single-phase Buck as EA was carried out. The behavior of the two-phase converter is completely different to that of the single-phase Buck studied in [33] as it will be shown in this section, because the two-phase operation cancels the switching-frequency component in the output filter. Due to this, the design procedure must be focused on the attenuation of the lower side band generated by the PWM modulation instead of the switching frequency, as in [33]. A study of the operation of the converter, along with a filter selection and performance evaluation procedure, is presented next.

\section{A. Converter Operation and Derivation of the Transfer Functions}

Fig. 3 shows two possible implementations of two-phase Buck converters with fourth-order output filters. The value of their reactive elements is referred to the corresponding singlephase Buck converter shown in Fig. 2(a) [33]. The second implementation [see Fig. 3(b)] exhibits superior performance because it has more reactive elements in the common part of both branches (three instead of one). Thus, only one pair of components $\left(L_{1 A}-L_{1 B}\right)$ instead of three $\left(L_{1 A}-L_{1 B}, C_{2 A}-C_{2 B}\right.$, and $L_{3 A}-L_{3 B}$ ) must be matched to have the same value. 


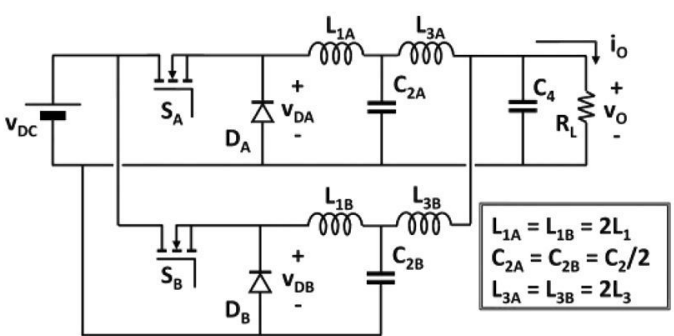

(a)

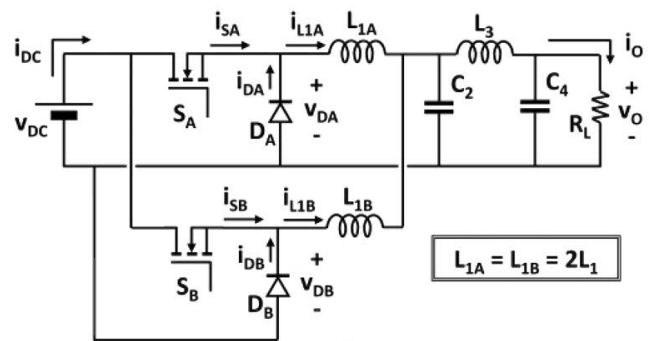

(b)

Fig. 3. Two possible implementations of a two-phase Buck converter with a fourth-order output filter. In all cases, the values of the reactive elements shown in these converters are referred to those given in Fig. 2(a). (a) Implementation sharing only one reactive element. (b) Implementation sharing three reactive elements.

As mentioned previously, the operation in CCM is mandatory to guarantee an appropriate tracking of the envelope. If the converter diodes $D_{A}$ and $D_{B}$ are replaced with MOSFETs (synchronous two-phase Buck converter), then the converter can always operate in CCM (DCM is not possible in these conditions because the synchronous rectifiers can conduct current in both directions). On the other hand, DCM is possible using diodes as main rectifiers. The conditions to operate in CCM are, in general, similar to those given in [33] for a one-phase Buck converter, modified to account for the fact that the average current passing through $L_{1 A}$ and $L_{1 B}$ is approximately one half of the load current. However, a detailed analysis is out of the scope of this paper.

The equivalent circuit of this converter when $L_{1 A}$ and $L_{1 B}$ are operating in the CCM is given in Fig. 4(a), where the switching networks $\left(S_{A}-D_{A}\right.$ and $\left.S_{B}-D_{B}\right)$ have been replaced with two ideal voltage sources $v_{\mathrm{DA}}$ and $v_{\mathrm{DB}}$, whose voltages coincide with the voltages across diodes $D_{A}$ and $D_{B}$, respectively.

It is assumed that the two phases are operated in a conventional multiphase manner: $v_{\mathrm{DA}}$ and $v_{\mathrm{DB}}$ have the same duty cycle over a switching period, but are $180^{\circ}$ out of phase, i.e., there is a delay of $T_{s} / 2$ between them, $T_{s}$ being the switching period (i.e., $T_{s}=1 / f_{s}$ ). The circuit given in Fig. 4(a) can be studied applying the superposition principle, thus obtaining the circuits shown in Fig. 4(b) and 4(c). These circuits can be simplified using Thévenin's theorem as depicted in Fig. 5(a) and Fig. 5(b). Therefore, the output voltage obtained from the circuit given in Fig. 5(a) will be

$$
v_{\mathrm{OA}}=H_{F}(s) \cdot v_{\mathrm{DA}} / 2
$$

$H_{F}(s)$ being the transfer function of the filter defined by $L_{1}, C_{2}, L_{3}, C_{4}$ and $R_{L}$. Similarly, the output voltage obtained

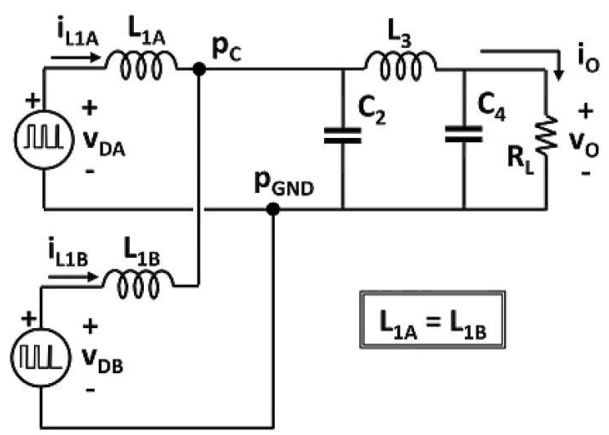

(a)

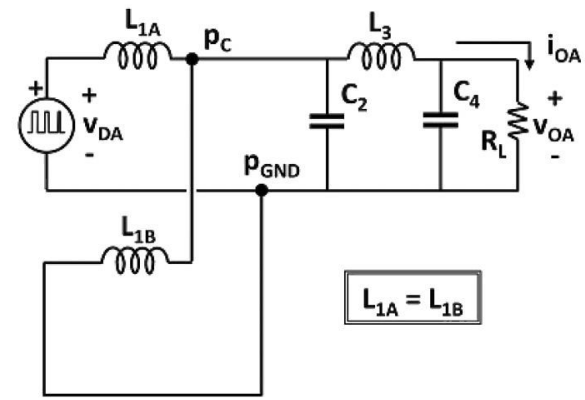

(b)

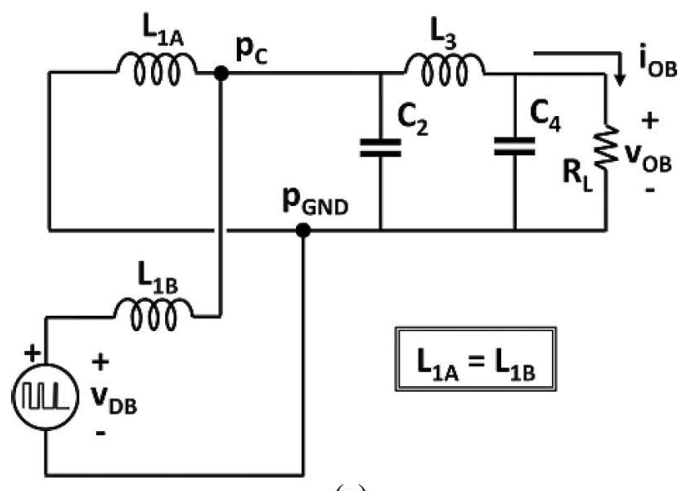

(c)

Fig. 4. (a) Equivalent circuit for the converter shown in Fig. 3(b) when it is working in the CCM. (b) According to the superposition principle, equivalent circuit when $v_{\mathrm{DB}}=0$. (c) Equivalent circuit when $v_{\mathrm{DA}}=0$.

from the circuit shown in Fig. 5(b) will be

$$
v_{\mathrm{OB}}=H_{F}(s) \cdot v_{\mathrm{DB}} / 2 .
$$

According to the superposition principle, the actual value of the output voltage will be

$$
v_{O}=v_{\mathrm{OA}}+v_{\mathrm{OB}}=H_{F}(s) \cdot\left(v_{\mathrm{DA}}+v_{\mathrm{DB}}\right) / 2 .
$$

The circuit corresponding to this equation is depicted in Fig. 5(c). As mentioned previously, voltage sources $v_{\mathrm{DA}}$ and $v_{\mathrm{DB}}$ are not independent. Taking $v_{\mathrm{DA}}$ as the reference phase, $v_{\mathrm{DB}}$ can be expressed as

$$
v_{\mathrm{DB}}=v_{\mathrm{DA}} \cdot e^{\frac{-T_{s}}{2} s} .
$$

From this (3) can be rewritten as follows:

$$
v_{O}=H_{F}(s) \cdot H_{D}(s) \cdot v_{\mathrm{DA}}
$$




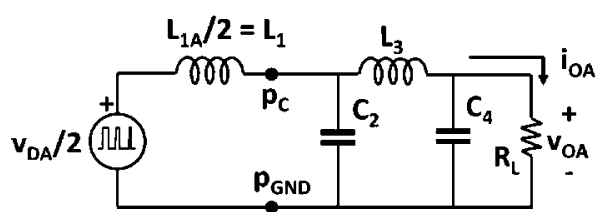

(a)

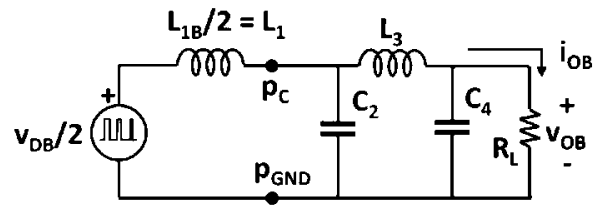

(b)

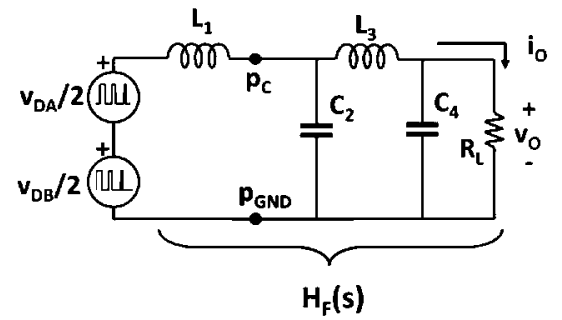

(c)

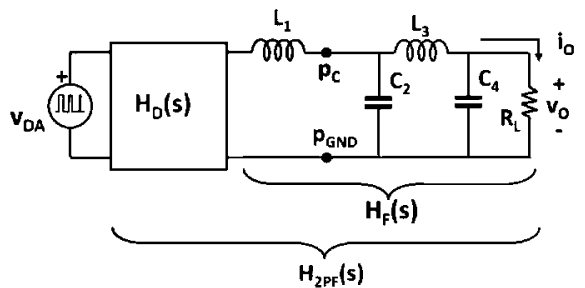

(d)

Fig. 5. (a) Thévenin's equivalent for the circuit given in Fig. 4(b). (b) Thévenin's equivalent for the circuit given in Fig. 4(c). (c) Equivalent circuit obtained applying superposition principle. (d) Final equivalent circuit taken into account the relationship between $v_{\mathrm{DA}}$ and $v_{\mathrm{DB}}$.

the transfer function $H_{D}(s)$ being

$$
H_{D}(s)=\frac{1+e^{\frac{-T_{s}}{2} s}}{2} .
$$

Therefore, the transfer function between $v_{\mathrm{DA}}$ and $v_{O}$ will be

$$
v_{O} / v_{\mathrm{DA}}=H_{2 \mathrm{PF}}(s)=H_{F}(s) \cdot H_{D}(s) .
$$

Equation (7) shows that the transfer function between the voltage $v_{\mathrm{DA}}$ across one of the two switching networks, and the output voltage $v_{O}$ can be computed as the product of the transfer function of a standard filter $H_{F}(s)$ multiplied by the transfer function $H_{D}(s)$, which takes into account the effect of the two-phase operation. Analyzing $H_{D}(s)$ in the frequency domain (by replacing the Laplace variable s with $\omega \cdot j$ ) and taking into account Euler's formula, it is easily found that $H_{D}\left(\omega_{S}\right)=$ 0 . This means that the function $H_{D}(s)$ introduces a notch filter effect at the angular switching frequency, which is desirable because it contributes to decrease the output voltage ripple.

This analysis can be easily extended to the use of $N$ phases. Assuming that the phase shift of phase $i$ expressed in radians is

$$
\varphi_{i}=\frac{(i-1)}{N} 2 \pi
$$

the transfer function $H_{D, N}$ can be expressed as

$$
H_{D, N}(s)=\frac{1}{N} \sum_{k=1}^{N} e^{-\frac{T_{s}}{N}(k-1) s} .
$$

Replacing $s$ with $\omega j$ to study the frequency response of $H_{D, N}$, we obtain

$$
H_{D, N}(\omega)=\frac{1}{N} \sum_{k=1}^{N} e^{-\frac{T_{s}}{N}(k-1) \omega j}
$$

Equation (10) resembles the Fourier transform of a rectangular window [34] and, therefore

$$
H_{D, N}(\omega)=\frac{1}{N} \cdot \frac{e^{\frac{-T_{s}}{2} \omega j}}{e^{\frac{-T_{s}}{2 N} \omega j}} \cdot \frac{\sin \left(\frac{1}{2} T_{s} \omega\right)}{\sin \left(\frac{1}{2} T_{s} \frac{\omega}{N}\right)} .
$$

Finally, the magnitude of $H_{D, N}(\omega)$ is

$$
\left|H_{D, N}(\omega)\right|=\left|\frac{1}{N} \frac{\sin \left(\frac{1}{2} T_{s} \omega\right)}{\sin \left(\frac{1}{2} T_{s} \frac{\omega}{N}\right)}\right| .
$$

This transfer function has transmission zeros at the angular frequencies

$$
\omega_{z, k}=k \omega_{s}, k \neq m N, \quad m=1,2,3 \ldots
$$

i.e., at the switching frequency $\omega_{s}$ and all its harmonics $k \omega_{s}$, except those that are integer multiples of $N \omega_{s}$. Due to the enhanced filtering effect provided by the high-order filters, the cancellation provided by use of additional phases does not significantly improve the performance of the Buck EA. This fact will be related more clearly to the presence of lower side bands of the signal in Section III. Therefore, this study focuses on the study of two-phase Buck EAs.

\section{B. Filter Selection}

Many different types of low-pass filters can be considered to be used as a standard filter $H_{F}(s)$. Butterworth, Chevyshev, Bessel-Thomson, Legendre-Papoulis, and Cauer filters are commonly used in many applications. Chevyshev filters have variable gain in the filter pass band, and Cauer (also called elliptic) filters have a huge rejection of specific frequencies, but they cannot guarantee enough rejection in a wide range of frequencies (as it is the case of the voltage in both switching networks). Due to this, Chevyshev and Cauer type filters are not very attractive to be used as output filter of a multiphase Buck converter used as EA. On the other hand, Bessel-Thomson, Butterworth, and Legendre-Papoulis have good characteristic to be considered as potential candidates for the aforementioned use. The procedure in [33] is used here to analyse the performance of the different filters.

Table I shows the transfer functions of the fourth-order versions of the aforementioned filters [35]-[37], normalized to an angular cut-off frequency $\omega_{c}$ of $1 \mathrm{rad} / \mathrm{s}$. The transfer function $H_{F}(s)$ corresponding to the conventional Bessel-Thomson filter and the complete transfer function $H_{2 \mathrm{PF}}(s)$ corresponding to the Bessel-Thomson filter operating in a two-phase Buck converter are plotted in Fig. 6; in this case the angular switching frequency has been chosen as $\omega_{s}=4 \mathrm{rad} / \mathrm{s}$. As Fig. 6 shows, the 
TABLE I

Transfer Functions of THE FOURTH-ORDER FiLTERS CONSIDERED IN THIS STUDY

\begin{tabular}{|c|c|}
\hline $\begin{array}{l}\text { Bessel- } \\
\text { Thomson }\end{array}$ & $\frac{105}{105+221.96 s+201.1 s^{2}+94.464 s^{3}+19.969 s^{4}}$ \\
\hline Butterworth & $\frac{1}{1+2.6131 s+3.4142 s^{2}+2.6131 s^{3}+s^{4}}$ \\
\hline $\begin{array}{l}\text { Legendre- } \\
\text { Papoulis }\end{array}$ & $\frac{0.40821577}{0.40821577+1.2415 s+1.8879 s^{2}+1.5628 s^{3}+s^{4}}$ \\
\hline
\end{tabular}

Gain [dB]

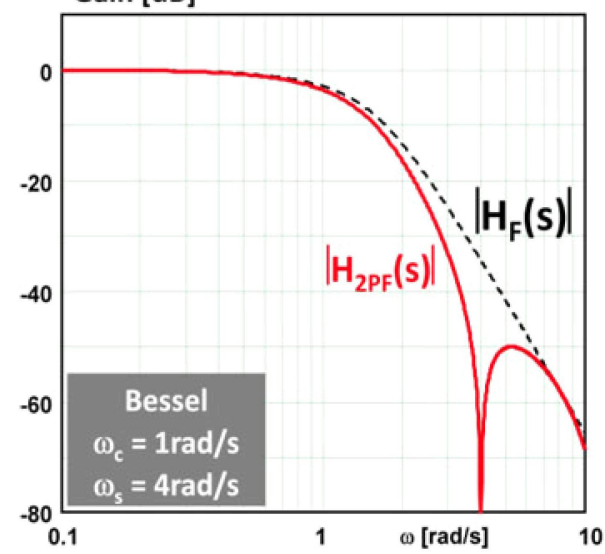

Fig. 6. Gain Bode plots of the transfer functions $H_{F}(s)$ and $H_{2 \mathrm{PF}}(s)$ for a fourth-order Bessel-Thomson filter when the filter cut-off angular frequency of $H_{F}(s)$ is $\omega_{c}=1 \mathrm{rad} / \mathrm{s}$ and the converter switching angular frequency is $\omega_{s}=$ $4 \mathrm{rad} / \mathrm{s}$.

transmission zero at $\omega_{s}$ caused by the two-phase operation ideally eliminates the output ripple component corresponding to the switching frequency. This is the main difference with respect to the single-phase operation presented in [33]. On the other hand, at $2 \cdot \omega_{s}$ the signal is attenuated according to the fourthorder filter as in the case of a single-phase Buck converter [33], i.e., $H_{2 \mathrm{PF}}\left(2 \omega_{s} \mathrm{j}\right)=H_{F}\left(2 \omega_{s} j\right)$ because $H_{D}\left(2 \omega_{s} j\right)=1$.

The transfer functions $H_{2 \mathrm{PF}}(s)$ of the three types of filters under study are plotted in Fig. 7. It can be seen that the Butterworth filter exhibits higher attenuation than the BesselThomson for the same angular frequency, but lower than the Legendre-Papoulis. Therefore, the Legendre-Papoulis filter exhibits superior performance with respect to attenuation.

However, the behavior of these filters in the pass band must also be considered. Fig. 8 shows the gain of the filters along with the relative variation of the group delay corresponding to these filters in the pass band. The group delay $\tau(\omega)$ is defined as

$$
\tau(\omega)=-d \phi(\omega) / d \omega
$$

$\phi(\omega)$ being the phase of the filter transfer function. Note that a constant group delay over the pass band can be easily compensated by introducing a delay in the signal path (see Fig. 1). However, a variable group delay in the pass band might cause distortion in the output voltage waveform. The relative

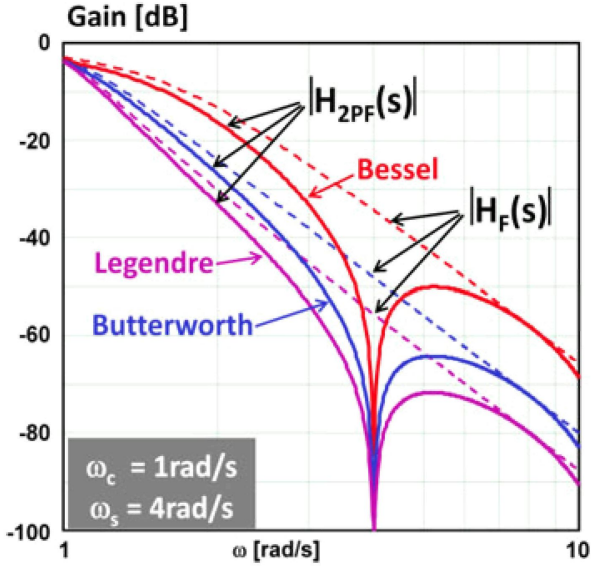

Fig. 7. Gain Bode plots of the transfer functions $H_{F}(s)$ and $H_{2 \mathrm{PF}}(s)$ for fourth-order Bessel-Thomson, Butterworth, and Legendre-Papoulis filters. In all these cases, the filter cut-off angular frequency of $H_{F}(s)$ is $\omega_{c}=1 \mathrm{rad} / \mathrm{s}$ and the converter switching angular frequency is $\omega_{s}=4 \mathrm{rad} / \mathrm{s}$.
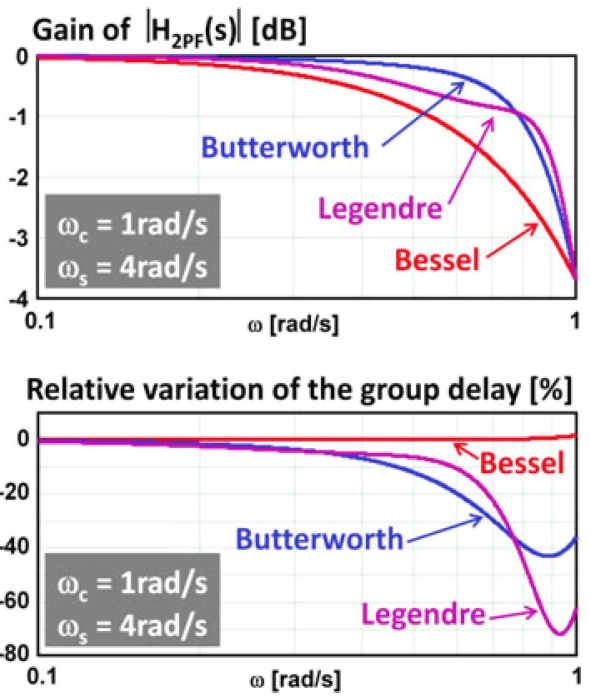

Fig. 8. Gain Bode plots and relative variations of the group delay corresponding to the transfer function $H_{2} \mathrm{PF}(s)$ for fourth-order Bessel-Thomson, Butterworth, and Legendre-Papoulis filters. In all these cases, the filter cut-off angular frequency of $H_{F}(s)$ is $\omega_{c}=1 \mathrm{rad} / \mathrm{s}$ and the converter angular switching frequency is $\omega_{s}=4 \mathrm{rad} / \mathrm{s}$.

variation of the group delay with respect to the group delay at $\mathrm{DC}$ is defined as

$$
\tau_{r}(\omega)=[\tau(\omega)-\tau(0)] / \tau(0)
$$

Fig. 8 shows that Bessel-Thomson filters exhibit superior performances from the point of view of relative variation of the group delay $\tau_{r}(\omega)$ in the pass band, but inferior performances from the point of view of attenuation in the pass band (which is not desired at all). On the other hand, Butterworth and Legendre-Papoulis filters present just the opposite performances, i.e., lower attenuation in the pass band but higher relative variation of the group delay. Hence, as in [33], a more detailed analysis is required in order to obtain practical information to select and design the proper filter. 


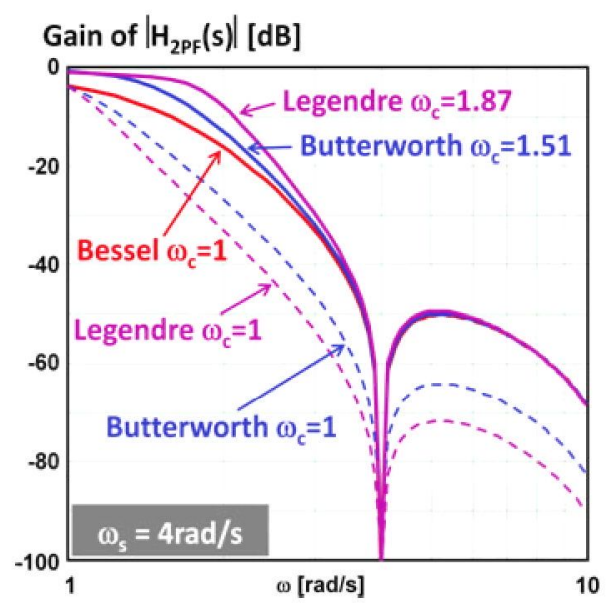

Fig. 9. Gain plots of the transfer functions $H_{2 \mathrm{PF}}(s)$ for fourth-order BesselThomson, Butterworth, and Legendre-Papoulis filters. In this case, the $H_{F}(s)$ cut-off angular frequency of is $\omega_{c}=1 \mathrm{rad} / \mathrm{s}$ for the Bessel-Thomson filter, but it has been increased up to $1.5075 \mathrm{rad} / \mathrm{s}$ in the case of the Butterworth filter and up to $1.8686 \mathrm{rad} / \mathrm{s}$ in the case of the Legendre-Papoulis filter to achieve the same attenuation $(58 \mathrm{~dB})$ at $2 \omega_{s}(8 \mathrm{rad} / \mathrm{s})$.

Noted that the behavior of these filters in the stop band is quite different (see Fig. 7), in spite of having been designed for the same cut-off angular frequency of $H_{F}(s)$, i.e., $\omega_{c}=1 \mathrm{rad} / \mathrm{s}$. Therefore, the value of $\omega_{c}$ of two of the filters should be modified in order to have similar behavior in the stop band, such that a fair comparison can be carried out. The cut-off angular frequencies of $H_{F}(s)$ for the Butterworth and Legendre-Papoulis filters have been appropriately increased to have similar attenuation to the Bessel-Thomson filter. In particular, these cut-off frequencies have been selected to be $\omega_{c}=1.5075 \mathrm{rad} / \mathrm{s}$ in the case of the Butterworth filter and $\omega_{c}=1.8686 \mathrm{rad} / \mathrm{s}$ in the case of the Legendre-Papoulis. With these values of $\omega_{c}$, the transfer function $H_{2 \mathrm{PF}}(s)$ for the three filters have identical attenuation at $2 \cdot \omega_{s}=8 \mathrm{rad} / \mathrm{s}(58 \mathrm{~dB})$ and very similar behavior at frequencies above $3 \mathrm{rad} / \mathrm{s}$, as shown in Fig. 9.

Once the filters have been adjusted to have similar behaviors in the stop band, the following quadratic error can be defined in order to quantify the overall tracking error:

$$
\begin{aligned}
e(\omega) & =\frac{\frac{1}{2 \pi} \int_{0}^{2 \pi} v_{\mathrm{dis}}(\omega, t)-v_{o}(\omega, t)^{2} \cdot d(\omega \cdot t)}{\frac{1}{2 \pi} \int_{0}^{2 \pi} \cos (\omega \cdot t)^{2} \cdot d t} \\
& \left.=\frac{1}{\pi} \int_{0}^{2 \pi} v_{\mathrm{dis}}(\omega, t)-v_{o}(\omega, t)\right)^{2} \cdot d(\omega \cdot t)
\end{aligned}
$$

$v_{\text {dis }}(\omega, t)$ being a signal of angular frequency $\omega$, unity amplitude and delayed $\tau(0)$, and $v_{O}(\omega, t)$ the same signal at the output of the filter. These quantities can be expressed as

$$
\begin{aligned}
v_{\mathrm{dis}}(\omega, t) & =\cos [\omega \cdot(t-\tau(0))] \\
v_{O}(\omega, t) & =\left|H_{2 \mathrm{PF}}(j \omega)\right| \cdot \cos \left[\omega t+\phi_{2 \mathrm{PF}}(j \omega)\right]
\end{aligned}
$$

$\tau(0)$ being the group delay at $d c$ and $\left|H_{2 \mathrm{PF}}(j \omega)\right|$ and $\phi_{2 \mathrm{PF}}(j \omega)$ the filter gain and the filter phase at $\omega \mathrm{rad} / \mathrm{s}$, respectively. It should be noted that these quantities also depend on the $H_{F}(s)$ cut-off frequency $\omega_{c}$.

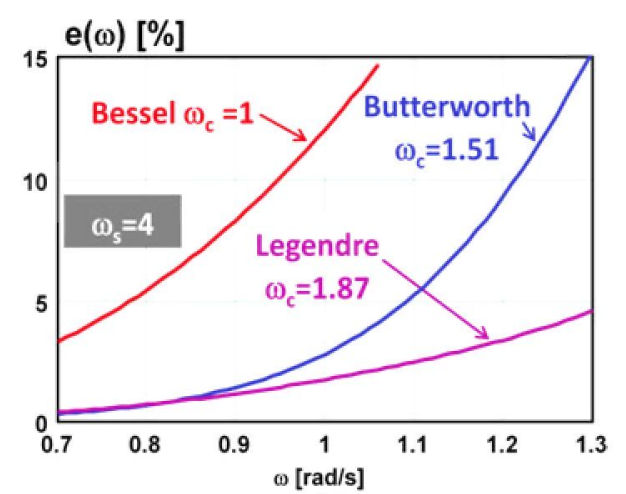

(a)

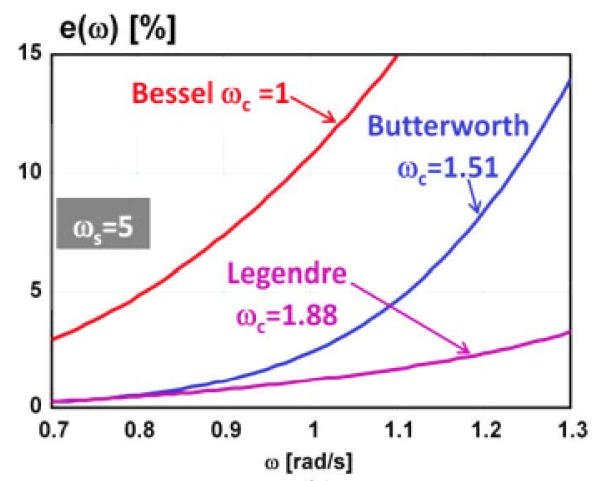

(b)

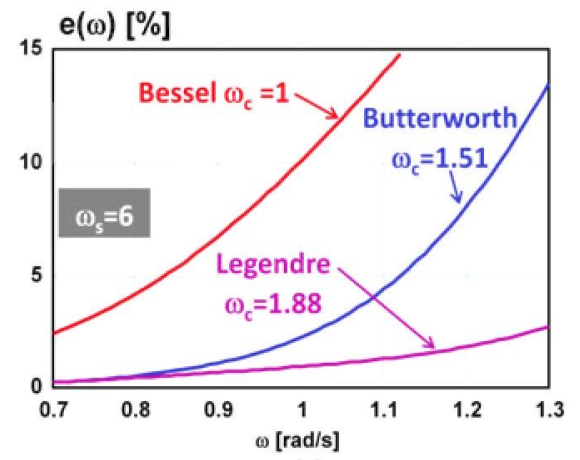

(c)

Fig. 10. Quadratic error reproducing the components at the upper end of the filter pass band. The filters have been modified as in Fig. 9. (a) $\omega_{s}=4 \mathrm{rad} / \mathrm{s}, \omega_{c}$ $=1.5075 \mathrm{rad} / \mathrm{s}$ for the Butterworth and $\omega_{c}=1.8686 \mathrm{rad} / \mathrm{s}$ for the LegendrePapoulis. (b) $\omega_{s}=5 \mathrm{rad} / \mathrm{s}, \omega_{c}=1.50998 \mathrm{rad} / \mathrm{s}$ for the Butterworth and $\omega_{c}=$ $1.87789 \mathrm{rad} / \mathrm{s}$ for the Legendre-Papoulis. c) $\omega_{s}=6 \mathrm{rad} / \mathrm{s}, \omega_{c}=1.5113 \mathrm{rad} / \mathrm{s}$ for the Butterworth and $\omega_{c}=1.8829 \mathrm{rad} / \mathrm{s}$ for the Legendre-Papoulis.

The results of the systematic calculation of this error for components of angular frequencies in the range $0.7-1.3 \mathrm{rad} / \mathrm{s}$ are shown in Fig. 10(a), with $\omega_{s}=4 \mathrm{rad} / \mathrm{s}$. This figure shows the superior performance of the fourth-order Legendre-Papoulis filter over the fourth-order Butterworth and Bessel-Thomson filters tracking components in the pass band of the filter when the three types of filters have similar behavior in the stop band. The frequencies below $1.3 \mathrm{rad} / \mathrm{s}$ are reproduced by the LegendrePapoulis filter with quadratic errors below $5 \%$, with $\omega_{c}=$ $1.8686 \mathrm{rad} / \mathrm{s}$ and $\omega_{s}=4 \mathrm{rad} / \mathrm{s}$. Therefore, the ratio between the angular switching frequency $\omega_{s}$ and the highest frequency component in the envelope that can be reproduced with a quadratic error less than $5 \%, \omega_{\text {env_max }}$, is $\omega_{s} / \omega_{\text {env_max }}=4 / 1.3=3.08$, 
which is an excellent result taking into account that the component of just $\omega_{s}$ is completely cancelled and the component of $2 \cdot \omega_{s}$ (i.e., $8 \mathrm{rad} / \mathrm{s}$ ) is attenuated $58 \mathrm{~dB}$ (see Fig. 9). Unfortunately, the PWM process generates side bands around the angular switching frequency and its harmonics, and the lower side band around the angular switching frequency is not cancelled by the notch filter effect of $H_{D}(s)$. This issue is addressed at the end of this section.

Fig. 10(b) and (c) show e $(\omega)$ for $\omega_{s}=5 \mathrm{rad} / \mathrm{s}$ and $\omega_{s}=6 \mathrm{rad} / \mathrm{s}$, respectively. When $\omega_{s}$ is increased to $6 \mathrm{rad} / \mathrm{s}$, the three filters have an attenuation of $72 \mathrm{~dB}$ at $2 \cdot \omega_{s}=12 \mathrm{rad} / \mathrm{s}$, with the corresponding adjustment in the cut-off frequencies of $H_{F}(s)\left(\omega_{c}\right.$ $=1.5113 \mathrm{rad} / \mathrm{s}$ for the Butterworth and $\omega_{c}=1.8829 \mathrm{rad} / \mathrm{s}$ for the Legendre-Papoulis). As expected, $e(\omega)$ of the LegendrePapoulis filter decreases: this quadratic error is now slightly above $3 \%$ for $\omega_{s} / \omega_{\text {env_max }}=3.85\left(\omega_{s}=5 \mathrm{rad} / \mathrm{s}\right)$, and below $3 \%$ for $\omega_{s} / \omega_{\text {env } \_ \text {max }}=4.6\left(\omega_{s}=6 \mathrm{rad} / \mathrm{s}\right)$. From Fig. 10(a), (b), and (c), it can be concluded that the fourth-order Legendre-Papoulis filter offers superior performance compared to the Butterworth and Bessel-Thomson filters. The conclusions can be straightforwardly extended to higher order filters.

\section{Filter Performance With Time-Varying Signals}

Compared to the single-phase Buck in [33], the two-phase Buck converter has the advantage of cancelling the switching frequency component in the output ripple. However, additional components around the switching frequency appear due to the fact that the operation as EA requires continuous variation of the duty cycle to produce the desired output waveform. The spectrum of the filter input voltage $v_{\mathrm{DA}}$ when a two-phase Buck is tracking a constant dc voltage is shown in Fig. 11(a). This spectrum has been obtained using Mathcad and it corresponds to the converter working at $\omega_{s}=4 \mathrm{rad} / \mathrm{s}$ with a constant duty cycle $d_{c}=0.5$. Given that the notch effect of $H_{D}(s)$ cancels all the odd harmonics (6), the first harmonic that will be found at the output will be at $2 \omega_{s}(8 \mathrm{rad} / \mathrm{s}$ in this case $)$. Note that in the particular case of $d_{c}=0.5, v_{\mathrm{DA}}$ only has odd harmonics of $\omega_{s}$, but it would have even and odd harmonics for any other $d_{c}$.

However, the situation changes dramatically when the converter is generating a variable output voltage to follow a specific envelope waveform. In this case, the duty cycle of $v_{\mathrm{DA}}$ is constantly changing according to the envelope signal and, therefore, its spectrum is much more complex. As is stated in [38] and [39], side bands appear around the harmonics of the switching frequency. Fig. 11(b) shows the spectrum of $v_{\mathrm{DA}}$ resulting from the tracking of a signal $x(t)$ :

$$
x(t)=0.5+0.5 \cdot \sin (0.2 t)+0.167 \cdot \sin (0.6 t)+0.1 \cdot \sin (t) .
$$

This signal corresponds to the first, third, and fifth harmonics of a square wave of duty cycle 0.5 and frequency $0.2 \mathrm{rad} / \mathrm{s}$. From Fig. 11, it can be appreciated that the harmonics are concentrated at specific frequencies in the case of a constant duty cycle [see Fig. 11(a)], but they are spread in complex side bands in the case of variable duty cycle (see Fig. 11(b), obtained using Mathcad). It should be noted that these side bands are not cancelled by the multiphase operation because they do not lay on
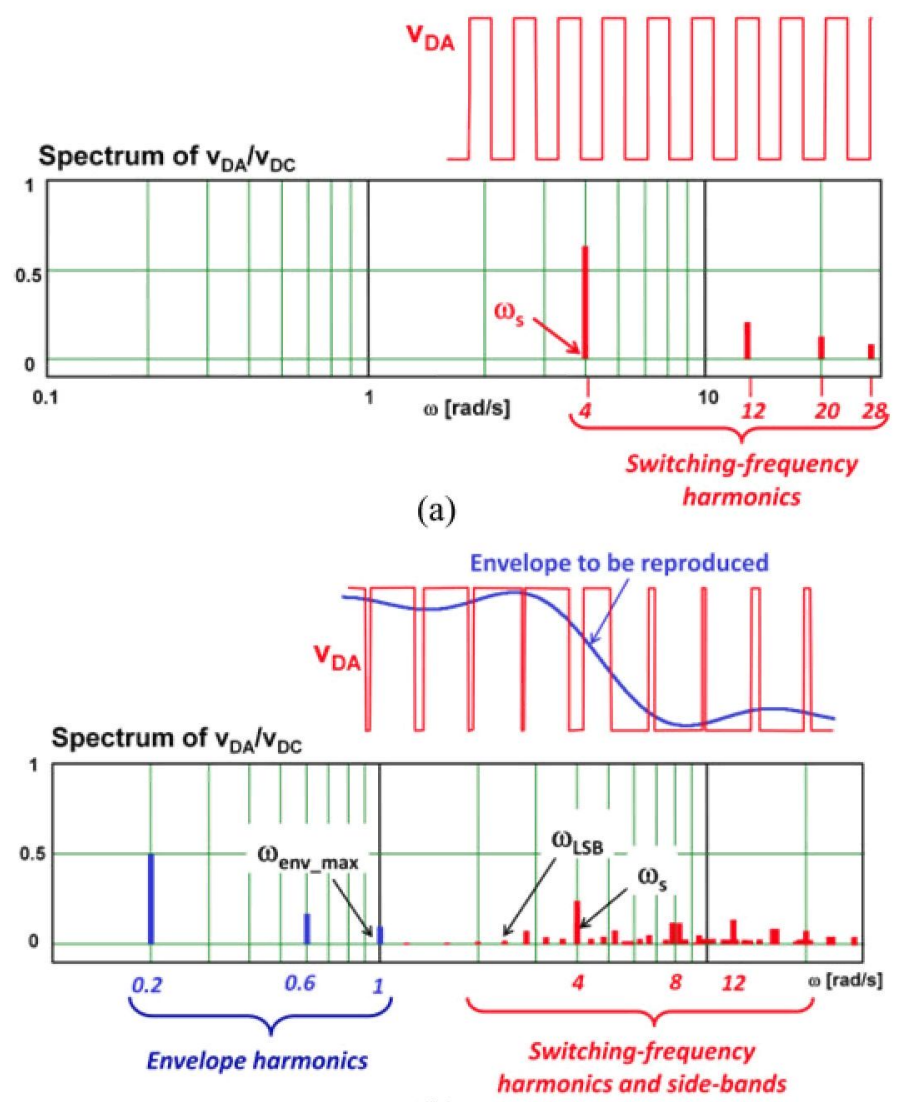

(b)

Fig. 11. (a) Spectrum of $v_{\mathrm{DA}} / v_{\mathrm{DC}}$ when the converter is reproducing a constant de voltage. (b) Spectrum of $v_{\mathrm{DA}} / v_{\mathrm{DC}}$ when the converter is reproducing a time-varying envelope.

multiples of $\omega_{s}$. Therefore, components around the switching frequency will be processed by the filter and will appear at the filter output, either contributing to the output-voltage ripple or increasing the envelope distortion. Fortunately, the amplitude of these side bands is clearly lower than the amplitude of the individual harmonics when the duty cycle is constant [38]. However, the effect of these side bands, especially the effect of the lower side band, must be taken into account when calculating the total output-voltage ripple and the output-voltage distortion. A general method to quantify the effect of the harmonics placed in this lower side band on the total output-voltage ripple is difficult to obtain because it depends on the particular envelope waveform being reproduced. A simplified approach suitable to design the output filters taking into account this effect is proposed in the following section.

\section{DESIGN OF LOW-PASS LEGENDRE-PAPOULIS FILTERS FOR EA REPRODUCING BAND-LiMITED SIGNALS}

In this section, the design of the output filter of a two-phase Buck EA is addressed considering band-limited envelope signals. This is a typical case when the EA is used for ET applications, as well as when a linear-assisted switcher is used in the context of the EER technique [13]-[18]. In this case, the switching-mode converter reproduces the lowest part of the 


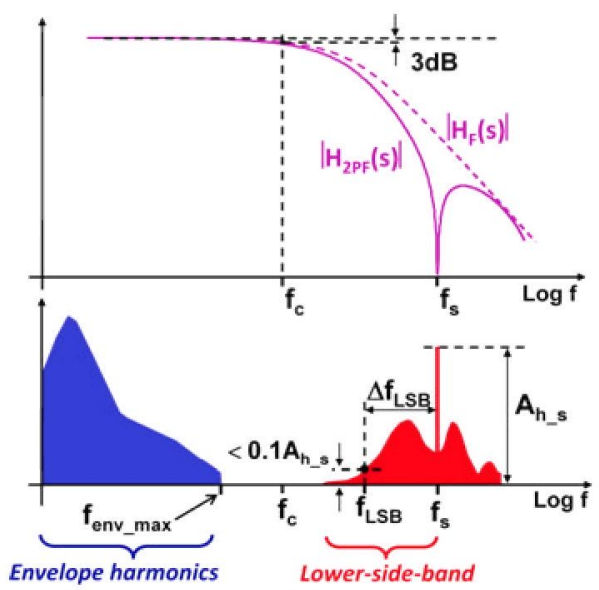

(a)



(b)

Fig. 12. (a) Main frequencies involved in the design of the two-phase Buck EA. (b) These same frequencies after being normalized.

envelope spectrum, whereas the linear reproduces the highest part of that spectrum. The switching-mode converter typically reproduces a band-limited signal corresponding to the lower part of the envelope spectrum.

\section{A. Design Procedure}

A Legendre-Papoulis filter is taken as an example due to its superior performance concluded from the analysis carried out in the previous section. All the frequencies involved in the design of a two-phase Buck EA reproducing a band-limited envelope are shown in Fig. 12(a). In this figure, $f_{\text {env_max }}$ is the highest frequency component in the envelope, $f_{c}$ is the cut-off frequency of the transfer function $H_{F}(s), f_{s}$ is the switching frequency, and $f_{\mathrm{LSB}}$ is the lowest switching-frequency harmonic that has a significant amplitude (e.g., its amplitude is $0.1 \cdot A_{h_{-}}, A_{h_{-} s}$ being the amplitude of the $f_{s}$ harmonic). From $f_{s}$ and $f_{\mathrm{LSB}}$, the lower side band bandwidth $\Delta f_{\mathrm{LSB}}$ is defined as

$$
\Delta f_{\mathrm{LSB}}=f_{s}-f_{\mathrm{LSB}} .
$$

As given in Fig. 12(b), $f_{c}, f_{s}, f_{\mathrm{LSB}}$ and $\Delta f_{\mathrm{LSB}}$ can be normalized to $f_{\text {env } \_ \text {max }}$. The result is as follows:

$$
\begin{aligned}
n f_{c} & =f_{c} / f_{\text {env_max }} \\
n f_{s} & =f_{s} / f_{\text {env_max }} \\
n f_{\mathrm{LSB}} & =f_{\mathrm{LSB}} / f_{\text {env_max }} \\
\delta_{\mathrm{LSB}} & =\Delta f_{\mathrm{LSB}} / f_{\text {env_max }} .
\end{aligned}
$$

The quadratic error $e_{h \_ \text {max }}$ (as defined in the previous section) corresponding to $f_{\text {env_max }}$ is represented in Fig. 13 for different



Fig. 13. Quadratic error reproducing the component of highest frequency in the envelope spectrum as a function of both the normalized switching frequency $n f_{s}$ and the normalized cut-off frequency $n f_{c}$. The filter of the two-phase Buck $\mathrm{EA}$ is a fourth-order Legendre-Papoulis one.

values of $n f_{s}$ and $n f_{c}$. As these figures shows, the value of $e_{h \text { max }}$ is almost constant for values of $n f_{s}$ higher than 4 . In this case, values of $n f_{c}$ higher than 1.3 guarantee that $e_{h_{-} \max }$ is lower than $5 \%$.

Once an accurate tracking of the envelope has been guaranteed, the output voltage ripple must be addressed. As mentioned in the previous section, this ripple is caused by the switching frequency harmonics and its side bands. The contribution of the second harmonic of the switching frequency $2 f_{s}$ to the overall ripple can be neglected due to the attenuation of the high-order output filter. The first harmonic is also cancelled by the notch filter effect of the two-phase operation.

However, the ripple caused by the lower side band of the switching frequency must be carefully considered, as these harmonics might appear close to $f_{\text {env _max }}$. Its impact strongly depends on the modulation index corresponding to each individual harmonic of the envelope [38]. To address this problem, the attenuation of the harmonic at frequency $n f_{\mathrm{LSB}}$ is considered [see Fig. 12(b)]. This attenuation depends on $n f_{s}$, on $n f_{c}$ (which is a function of $e_{h \_ \text {max }}$ and $n f_{s}$ according to Fig. 13) and on $\delta_{\mathrm{LSB}}$. For a given value of $n f_{c}$ [see Fig. 12(b)], the higher $n f_{s}$ and the lower $\delta_{\mathrm{LSB}}$, the stronger attenuation of $n f_{\mathrm{LSB}}$ is achieved.

As mentioned before, the attenuation of the harmonic at frequency $n f_{\mathrm{LSB}}$ is a function of $n f_{s}, \delta_{\mathrm{LSB}}$, and $n f_{c}$; the latter is in fact the function of $e_{h \_ \text {max }}$ and $n f_{s}$. Therefore, this attenuation can be expressed as a function of $n f_{s}, e_{h_{-} \max }$, and $\delta_{\mathrm{LSB}}$, as shown in Fig. 14. The plots in this figure allow calculating $n f_{s}$ for different types of envelope waveforms (different values of $\delta_{\mathrm{LSB}}$ ), different desired attenuations of $n f_{\mathrm{LSB}}$, and different values of the quadratic error $e_{h_{-} \text {max }}$. Note that Fig. 14 includes the main design parameters: envelope tracking error $e_{h \_ \text {max }}$ in the pass band and attenuation of side-band harmonics in the stop band.

As an example, let us evaluate the value of $\delta_{\mathrm{LSB}}$ corresponding to $v_{\mathrm{DA}}$ reproducing the envelope signal $x(t)$ given in (19) and shown in Fig. 11(b) when the converter angular switching frequency $\omega_{s}$ is $4 \mathrm{rad} / \mathrm{s}$. As (19) shows, the value of $\omega_{\text {env_max }}$ is $1 \mathrm{rad} / \mathrm{s}$. This means that $n f_{s}=4$. The amplitudes corresponding to the lower side band below the angular switching frequency 
TABLE II

Amplitude of the Harmonics in the Lower Side Band. $A_{h}$ is the Relative Amplitude OF the Harmonic Whose Angular Frequency is $\omega_{h}$.

\begin{tabular}{|c|c|c|c|c|c|c|c|c|c|c|c|}
\hline $\begin{array}{c}\omega_{\mathrm{h}} \\
{[\mathrm{rad} / \mathrm{s}]}\end{array}$ & 2 & 2.2 & 2.4 & 2.6 & 2.8 & 3 & 3.2 & 3.4 & 3.6 & 3.8 & 4 \\
\hline $\mathrm{A}_{\mathrm{h}}[\%]$ & 3.74 & - & 9.5 & - & 33 & - & 18.2 & - & 14.6 & 0.2 & 100 \\
\hline$\delta_{\mathrm{LSB}}$ & 2 & & 1.6 & & & & & & & & \\
\hline
\end{tabular}

$\mathrm{A}_{\mathrm{h}}$ is the relative amplitude of the harmonic whose angular frequency is $\omega_{\mathrm{h}}$. This amplitude has been normalized to the amplitude of the component of the angular switching frequency $\omega_{\mathrm{s}}(4 \mathrm{rad} / \mathrm{s})$.

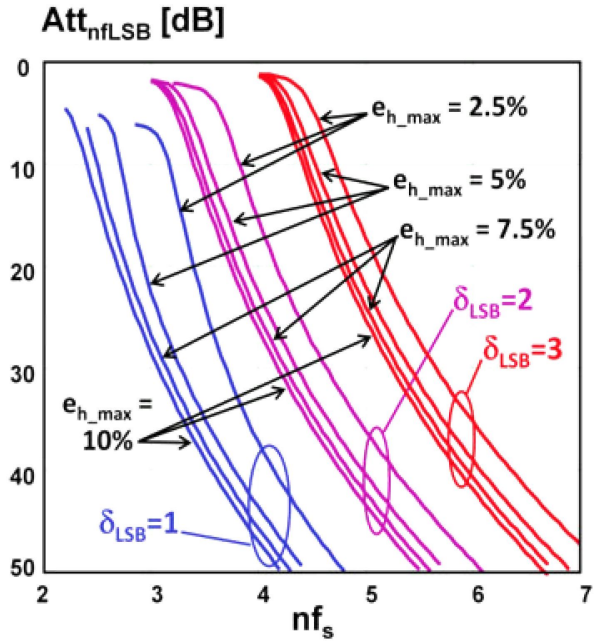

Fig. 14. Attenuation of the lowest-frequency harmonic in the lower side band next to the switching frequency $n f_{\mathrm{LSB}}$ as a function of $n f_{s}, \delta_{\mathrm{LSB}}$ and $e_{h \_ \text {max }}$.

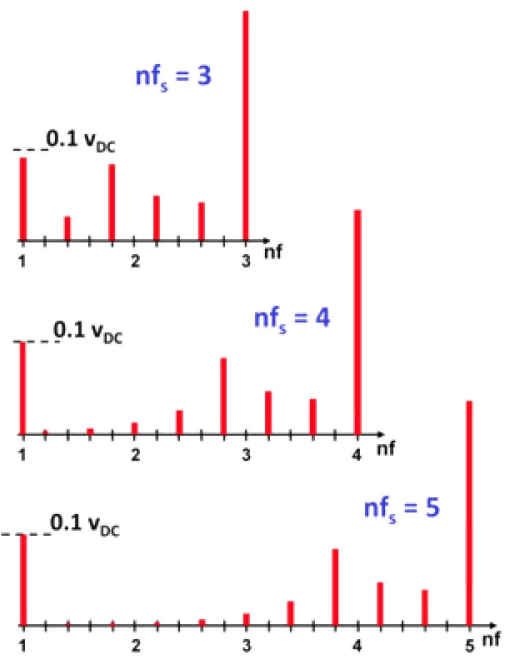

Fig. 15. Lower side band reproducing the signal given in (19) for different values of $n f_{s}$.

$\omega_{s}$ are given in Table II, normalized to the amplitude of the harmonic at $\omega_{s}$. As this table shows, the lowest frequency component with appreciable value (i.e., $f_{\mathrm{LSB}}$ ) can be considered to be at $2.4 \mathrm{rad} / \mathrm{s}(9.5 \%)$ or at $2 \mathrm{rad} / \mathrm{s}(3.74 \%)$. The value of $\delta_{\mathrm{LSB}}$ computed from (20) and (24) are shown in the table. Fig. 15 shows the evolution of the lower side band as $n f_{s}$ goes from 3 to 5 . The spectra shown in this figure has been obtained using Mathcad. As this figure shows, the lower side band has the same spectrum but shifted in frequency toward the pass band as $n f_{s}$ decreases: the amplitude of the component $\omega_{\text {env } \_ \text {max }}$ is slightly distorted by the side band when $n f_{s}=3$, and it is unaffected for $n f_{s}>3$.

\section{B. Design Example}

As an example, the output filter for a two-phase Buck EA whose switching frequency is $10 \mathrm{MHz}$ will be designed. The EA must reproduce the same waveform $x(t)$ as the one that has been considered previously, but of as high frequency as possible. The quadratic error corresponding to the highest harmonic $e_{h \_ \text {max }}$ of the original envelope must be below $7.5 \%$.

As a first attempt, the value of $\delta_{\mathrm{LSB}}$ has been selected to be 2 , which is a conservative assumption according to the previous considerations regarding the lower side band components given in Table II and shown in Fig. 15. Moreover, an attenuation of $40 \mathrm{~dB}$ for $f_{\mathrm{LSB}}$ and a quadratic error $e_{h_{-} \max }$ around $5 \%$ have been considered for this first design. From the design curves given in Fig. 14, we obtain $n f_{s}=5$. Taking into account these values for $n f_{s}$ and $e_{h \_ \text {max }}$, the value of $n f_{c}$ can be obtained directly from the plots given in Fig. 13, the result being $n f_{c}=1.3$ (see Fig. 16 as well). As the converter switching frequency is set to $f_{s}=10 \mathrm{MHz}$, the value of $f_{\text {env _max }}$ can be directly obtained from (22), the result being $f_{\text {env_max }}=10 / 5=2 \mathrm{MHz}$. This means that the fundamental frequency of the envelope signal to be reproduced in these conditions is $2 \mathrm{MHz} / 5=0.4 \mathrm{MHz}$. Once $f_{\text {env_max }}$ is known, the cut-off frequency of $H_{F}(s)$ can be directly calculated from (21), thus obtaining $f_{c}=1.3 \cdot 2=$ $2.6 \mathrm{MHz}$.

Fig. 17(a) shows the spectra corresponding to $v_{\mathrm{DA}}$ (filter input) and $v_{O}$ (filter output) for the case considered. The amplitude of each harmonic has been obtained using Mathcad, and it has been normalized to the converter input voltage $v_{\mathrm{DC}}$. It should be noted that the three components in the pass band have very little distortion, whereas all the components in the stop band are significantly attenuated (more than $70 \mathrm{~dB}$ ). As expected, the component corresponding to $f_{\mathrm{LSB}}=f_{s}-\delta_{\mathrm{LSB}} \cdot f_{\mathrm{env} \_ \text {max }}=$ $6 \mathrm{MHz}$ exhibits an attenuation of about $40 \mathrm{~dB}$.

In a second attempt, $\delta_{\mathrm{LSB}}$ is selected to be 1.6. In this case, a more challenging design is proposed, because the attenuation at $f_{\mathrm{LSB}}$ is only $14 \mathrm{~dB}$ (5 times). As a consequence, the harmonics of the lower side band will contribute to distort the envelope waveform. The quadratic error $e_{h \_ \text {max }}$ considered for this second design has been approximately $7.5 \%$. From the design plots given in Fig. 14, we obtain $n f_{s}=3.2$ (see Fig. 16(a) as well). The value of $n f_{c}$ can be obtained from these values of $n f_{s}$ and $e_{h \_ \text {max }}$ and from the plots given in Fig. 13, the result being 1.28 [also see Fig. 16(b)]; the value $n f_{c}=1.3$ has been selected for the rest of the calculations. The values of $f_{\text {env }}$ max and $f_{c}$ can be obtained directly from (22) and (21) taking into account that 


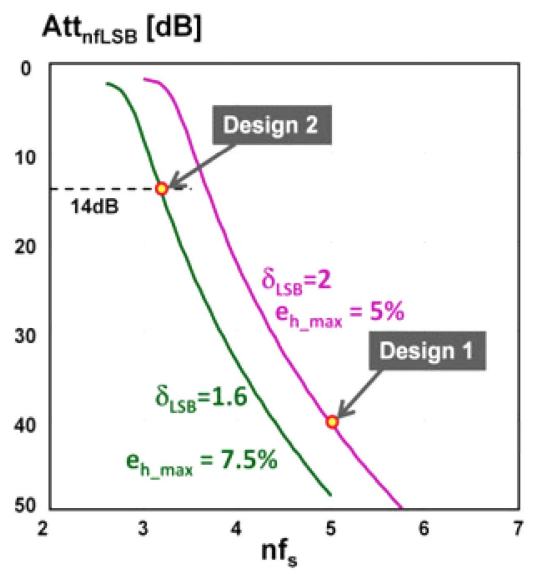

(a)



(b)

Fig. 16. (a) Design examples shown in Section III placed on the plots given in Fig. 14. (b) Design examples placed on the plots given in Fig. 13.

$f_{s}=10 \mathrm{MHz}$, the result being $f_{\text {env } \_ \text {max }}=10 / 3.2=3.125 \mathrm{MHz}$ and $f_{c}=1.3 \cdot 3.125=4.0625 \mathrm{MHz}$. This means that the fundamental frequency of the envelope signal can be $3.125 \mathrm{MHz} / 5=$ $0.625 \mathrm{MHz}$.

In this case, the amplitude of the harmonics corresponding to $v_{\text {DA }}$ and $v_{O}$ is given in Fig. 17(b). As in the previous case, the three components corresponding to the pass band do not suffer significant attenuation. On the other hand, the components in the stop band are attenuated (more than $40 \mathrm{~dB}$ ), but clearly less than in the previous case. The difference between the amplitudes corresponding to the highest frequency component in the pass band and the highest amplitude component in the stop band is only about $22 \mathrm{~dB}$. This fact will contribute to distort the envelope waveform obtained at the converter output.

\section{IMPLEMENTATION OF LOW-PASS LEGENDRE-PAPOULIS FILTERS FOR EA REPRODUCING BAND-LIMITED SIGNALS}

The implementation of low-pass filters based on inductors and capacitors can be easily found in many basic text books [35]-[37]. However, special attention must be paid to the type of voltage source connected at the filter input [33]. In the case of a switching converter, the implementation cannot be based on matching for maximum power transfer as the output resistance of the equivalent voltage source is $R_{g}=0 \Omega$. The right values of

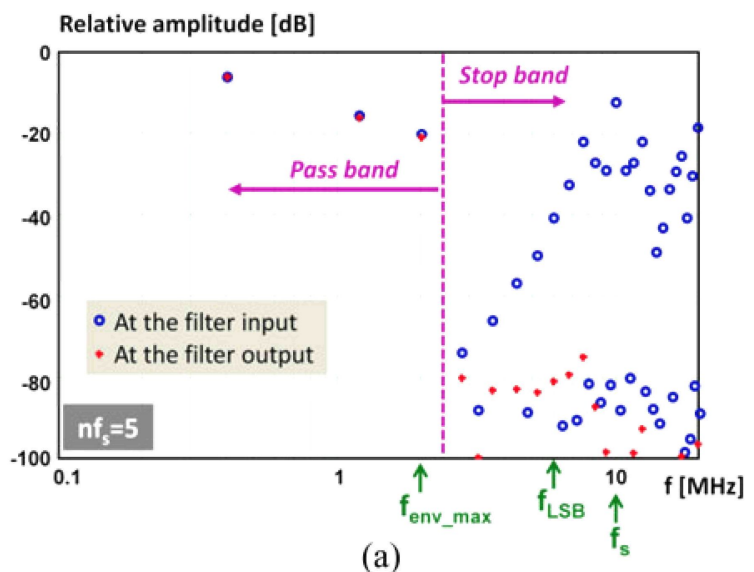

(a)

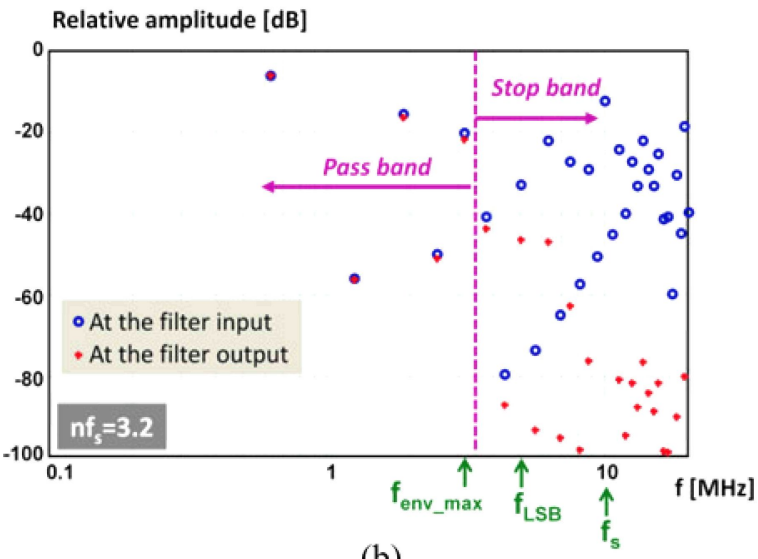

(b)

Fig. 17. Spectrum of $v_{\mathrm{DA}}$ (filter input) and of $v_{O}$ (filter output) when the converter is reproducing the envelope shown in Fig. 11(b). (a) Design with $n f_{s}=5$. (b) Design with $n f_{s}=3.2$.

TABLE III

Parameters to Calculate the Reactive Elements of a Fourth-ORder LEGENDRE-PAPOULIS FILTER USED IN THE TwO-PHASE BUCK EAS

\begin{tabular}{|c|c|c|c|}
\hline $1_{1 \mathrm{~A}}=1_{1 \mathrm{~B}}$ & $\mathrm{c}_{2}$ & $1_{3}$ & $\mathrm{c}_{4}$ \\
\hline 3.224 & 1.6616 & 1.4292 & 0.6399 \\
\hline
\end{tabular}

the filter elements in this case can be found in some handbooks and text books [37], [40], [41].

As shown in Fig. 3(b), the implementation of the output filter of a two-phase Buck EA can be easily obtained from the case of a single-phase Buck EA, because the only difference is the value of the two first inductors. In the case of the two-phase converter, the inductors have twice the value of the inductor of the single-phase Buck. The value of the inductors and capacitors for the filter can be easily calculated from the parameters given in Table III [36]. From these parameters, the actual values of the filter elements for a desired angular cut-off frequency $\omega_{c}$ and a load resistance $R_{L}$ can be easily calculated as follows:

$$
\begin{aligned}
L_{X} & =\frac{l_{X} \cdot R_{L}}{\omega_{c}} \\
C_{X} & =\frac{c_{X}}{\omega_{c} \cdot R_{L}} .
\end{aligned}
$$


TABLE IV

REACTIVE ELEMENTS OF THE LEGENDRE-PAPOUlis FiLTERS USED IN THE DESIGN EXAMPLES

\begin{tabular}{|c|c|c|c|c|c|}
\hline & $\begin{array}{c}\mathbf{f}_{\mathrm{c}} \\
{[\mathrm{MHz}]}\end{array}$ & $\begin{array}{c}\mathrm{L}_{1 \mathrm{~A}}=\mathrm{L}_{1 \mathrm{~B}} \\
{[\mathrm{nH}]}\end{array}$ & $\begin{array}{c}\mathrm{C}_{2} \\
{[\mathrm{nF}]}\end{array}$ & $\begin{array}{c}\mathrm{L}_{3} \\
{[\mathrm{nH}]}\end{array}$ & $\begin{array}{c}\mathrm{C}_{4} \\
{[\mathrm{nF}]}\end{array}$ \\
\hline $\begin{array}{c}\text { Design } \\
1\end{array}$ & 2.6 & 986.8 & 20.34 & 437.4 & 7.834 \\
\hline $\begin{array}{c}\text { Design } \\
2\end{array}$ & 4.0625 & 631.5 & 13.02 & 280 & 5.014 \\
\hline
\end{tabular}

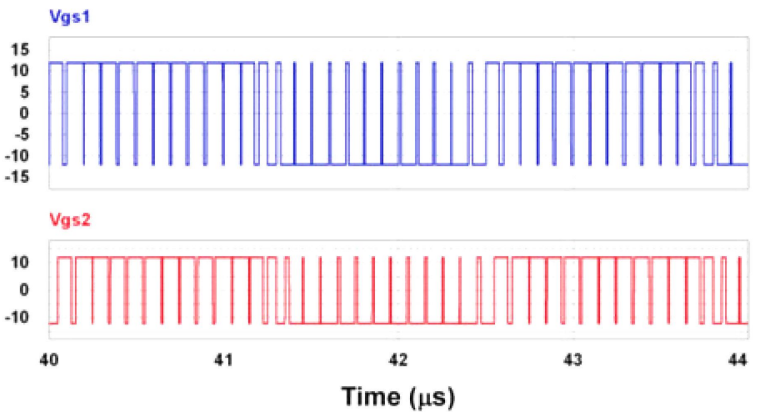

(a)

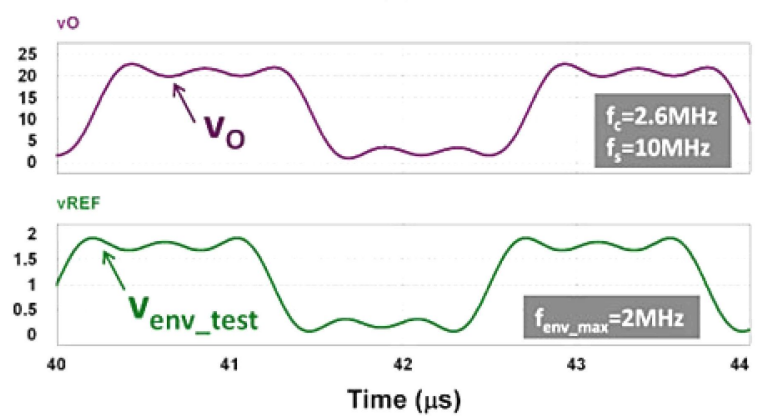

(b)

Fig. 18. Simulated results corresponding to the first design examples in Section III (Design 1): (a) MOSFET Gate signals. (b) Output voltage and reference voltage.

Obviously, the values of $L_{x}\left(C_{x}\right)$ and $l_{x}\left(c_{x}\right)$ coincide for the case of $R_{L}=1 \Omega$ and $\omega_{c}=1 \mathrm{rad} / \mathrm{s}$.

The values of the reactive elements for the design examples given in Section III can be easily calculated from (25) and (26) for a given value of the load $R_{L}$. For instance, the values of the reactive elements are shown in Table IV for $R_{L}=5 \Omega$.

\section{SimUlation AND EXPERIMENTAL RESUlts}

\section{A. Simulation Results}

The two design examples presented in Section III have been simulated using PSIM Simulation Software. The results corresponding to the first example are shown in Fig. 18. As this figure shows, the reference signal $v_{\text {env_test }}$ is reproduced accurately and without appreciable high-frequency ripple. The waveform corresponding to $v_{O}$ is delayed about $0.22 \mu \mathrm{s}$, which approximately corresponds to the group delay of a fourth-order Legendre-Papoulis filter with $f_{c}=2.6 \mathrm{MHz}$.

The results corresponding to the second example presented in Section III are given in Fig. 19. As mentioned in that section, this

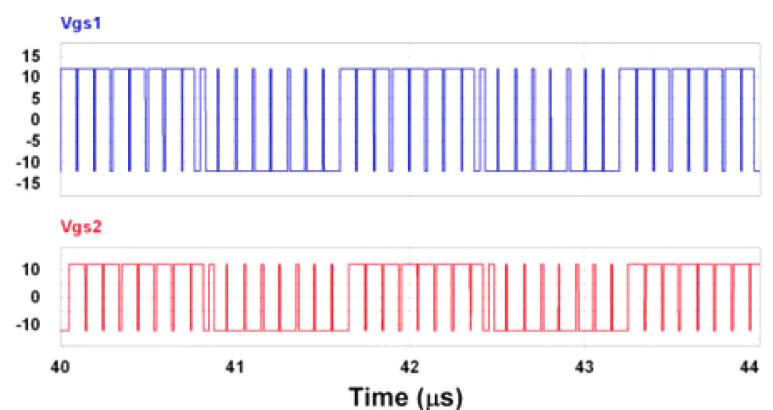

(a)

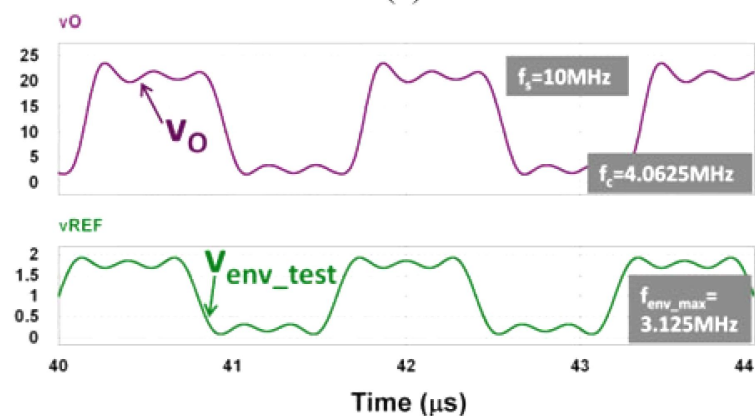

(b)

Fig. 19. Simulated results corresponding to the second design examples in Section III (Design 2): (a) MOSFET Gate signals. (b) Output voltage and reference voltage.

is a more challenging (and risky) design because the component of the highest frequency in the pass band and the component of the lowest frequency in the stop band are separated by only $22 \mathrm{~dB}$. As a consequence, the output voltage waveform $v_{O}$ has a slight distortion in both the high state and the low state [see the asymmetrical ringing in these states, Fig. 19(b)]. The delay between both waveforms is, in this case, about $0.15 \mu \mathrm{s}$.

\section{B. Experimental Results}

Two prototypes of two-phase Buck converters with Legendre-Papoulis filters and with the specifications corresponding to the design examples given in Section III have been built and tested. The converter input voltage is $28 \mathrm{~V}$ and the load is $5 \Omega$. The power handled at maximum output voltage is $100 \mathrm{~W}$.

In a Buck EA, switching frequencies in the range of several megahertz are not uncommon to achieve the required bandwidths. This high operating frequencies cause a significant reduction of the converter efficiency due to increased switching losses. This makes it difficult to use commercial Si or GaN FETs in this application.

An alternative is to use Si-LDMOS RF devices as power transistors. These devices can be used in RF amplifiers up to frequencies of $1 \mathrm{GHz}$ due to their low value of parasitic capacitances and fast switching times. For this reason, RF transistor PD55008 Si-LDMOS (ST Microelectronics) has been selected to be used in the prototypes. Three different power diodes (MBRS140, STPS1L40 A and DFLS140) were evaluated by measuring the converter efficiency at different switching frequencies (6 and 


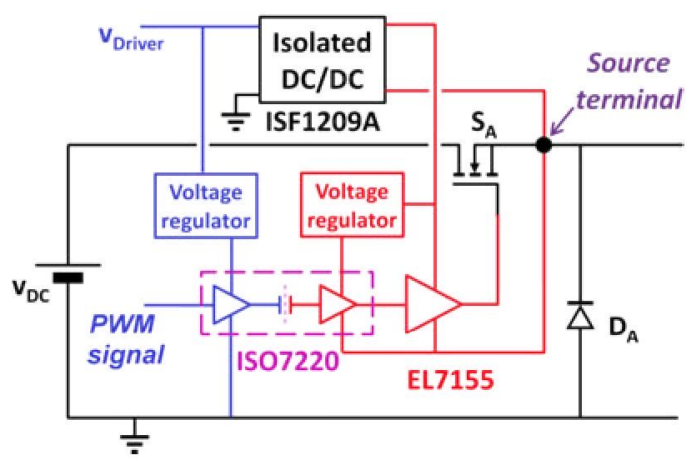

Fig. 20. Driving system for each power MOSFET.

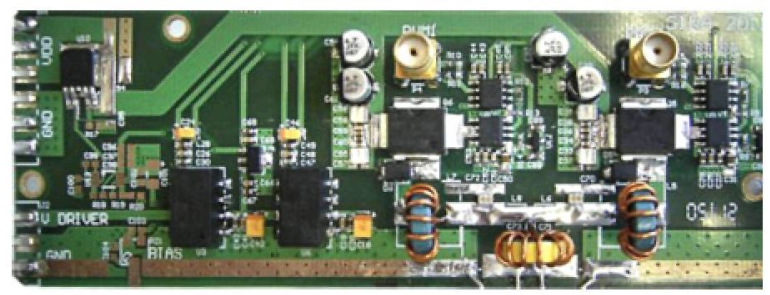

Fig. 21. Photograph of one of the two prototypes.

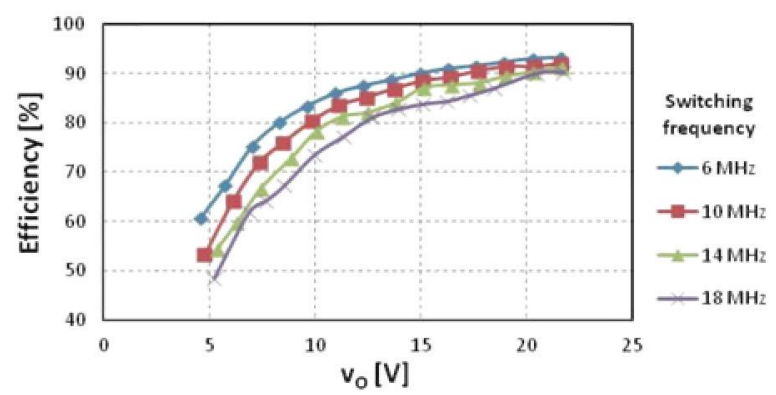

Fig. 22. Converter efficiency as a function of the output voltage for different switching frequencies.

$10 \mathrm{MHz}$ ) and duty cycles (from 0.1 to 0.9 ). Diode MBRS 140 was finally selected due to its better performance.

An isolated driver (see Fig. 20) made up of an isolation barrier, a high speed gate driver, and a floating power supply was used to allow operation of the high-side device at very high frequencies, as well as to provide additional flexibility. The isolation barrier is the dual-channel digital isolator ISO7220 (Texas Instruments), which provides fast operation with signalling rates from $\mathrm{dc}$ to $150 \mathrm{Mb} / \mathrm{s}$. The actual gate drive circuit is the EL7155 (Intersil), which is designed for clocking speeds up to $40 \mathrm{MHz}$. Finally, the floating power supply has been implemented using a fully integrated isolated $\mathrm{dc} / \mathrm{dc}$ converter ISF1209 A (XP Power), which has low input to output capacitance. Fig. 21 shows a photograph of one of the two prototypes used to obtain the experimental results.

The converter efficiency as a function of the output voltage and for different switching frequencies is given in Fig. 22. These results have been obtained with the converter operating in steady state to obtain different values of the output voltage. It should be noted that the efficiency remains in the range of $80 \%-90 \%$ for output voltages in the range of $10-22 \mathrm{~V}$, even at switching frequencies as high as $14 \mathrm{MHz}$. The relatively weak influence of the switching frequency on the converter efficiency suggests that switching losses are relatively low due to the low parasitic capacitances of the power devices selected for this application and, therefore, the majority of losses are conduction losses. As also Fig. 22 shows, the converter efficiency decreases from about $80 \%$ to only $60 \%-50 \%$ when the output voltage decreases to $5 \mathrm{~V}$. This is mainly due to the losses in the driving circuitry, which have been taken into account when computing the overall efficiency shown in Fig. 22. This fact can be clearly observed in Tables V and VI, where the losses in different parts of the converter are shown for several output voltage values when the converter is switching at $10 \mathrm{MHz}$. As Table V shows, the driving losses remain almost constant when the converter output voltage changes, which means that they have a significant impact on the converter efficiency at the low output voltage (i.e., at low power). On the other hand, this impact is quite limited at the high output voltage (i.e., at high power). The percentage that these losses represent is given in Table VI.

In the final prototype, a switching frequency of $10 \mathrm{MHz}$ has been selected to test the behavior of the converter as EA. Once the switching frequency has been selected, the values of the reactive components used are those shown in Table IV. Details about the implementation of these reactive elements are given in Table VII. The load has been emulated using two resistors of $10 \Omega / 50$ W LTO050F10R00JTE3 (Vishay/Sfernice) connected in parallel.

The PWM signals used to drive the converter is generated by a software-controlled arbitrary waveform generator Agilent 81150 A. A PC running a MATLAB script generates the test signal, which is pulse-width modulated and stored in the function generator in order to control the converter.

Figs. 23 and 24 show the results obtained from these prototypes. The voltage ripple across $C_{2}$ and across the load when the converter is operating with a fixed value of the duty cycle $\left(d_{c}=\right.$ 0.75 ) are shown in Fig. 23(a) (Design 1) and Fig. 24(a) (Design 2 ). As these figures show, the output voltage ripple is low in both cases: about $20 \mathrm{mV}$ peak-to-peak in the case of Design 1 and $37 \mathrm{mV}$ peak-to-peak in the case of Design 2, in both cases when the output voltage is $21 \mathrm{~V}$.

The current passing through $L_{1 A}$ and $L_{1 B}$ is also shown in these figures.

Fig. 23(b) shows the main waveforms obtained when the test signal $v_{\text {env-test }}$ is reproduced by the prototype corresponding to Design 1. It should be noted that the envelope waveform reproduced here has components at dc, $400 \mathrm{kHz}, 1.2 \mathrm{MHz}$, and $2 \mathrm{MHz}$. As this figure shows, $v_{\text {env }- \text { test }}$ is accurately reproduced. Note that the output voltage $v_{0}$ does not have appreciable switching-frequency voltage ripple. Moreover, the results obtained are in good agreement with those in Fig. 18(b).

The results obtained with the prototype corresponding to Design 2 are shown in Fig. 24(b). The envelope waveform reproduced in this case has components at dc, $625 \mathrm{kHz}, 1.875 \mathrm{MHz}$, and $3.125 \mathrm{MHz}$. The output voltage waveform exhibits a slight distortion due to the lowest frequency harmonics in the lower side band, as expected (asymmetrical ringing). However, the 
TABLE V

POWER Losses AT 10 MHz FOR DifFERENT OUTPut VoltaGES

\begin{tabular}{|c|c|c|c|c|c|c|c|}
\hline $\begin{array}{c}v_{O}[\mathrm{~V}] \\
\left(R_{L}=5 \Omega\right)\end{array}$ & $\begin{array}{c}\text { Output } \\
\text { Power } \\
{[\mathrm{W}]}\end{array}$ & $\begin{array}{c}\text { Efficiency } \\
{[\%]} \\
\text { (measured) }\end{array}$ & $\begin{array}{c}\text { Total } \\
\text { losses [W] } \\
\text { (measured) }\end{array}$ & $\begin{array}{c}\text { Driving } \\
\text { losses [W] } \\
\text { (measured) }\end{array}$ & $\begin{array}{c}\text { Power stage } \\
\text { losses [W] } \\
\text { (measured) }\end{array}$ & $\begin{array}{c}\text { Power } \\
\text { devices } \\
\text { losses [W] } \\
\text { (simulated) }\end{array}$ & $\begin{array}{c}\text { Other } \\
\text { losses [W] }\end{array}$ \\
\hline 6.11 & 7.47 & 64.21 & 4.17 & 2.14 & 2.03 & 1.57 & 0.46 \\
\hline 9.88 & 19.52 & 80.53 & 4.72 & 2.21 & 2.51 & 2.19 & 0.32 \\
\hline 12.42 & 30.85 & 85.20 & 5.36 & 2.30 & 3.06 & 2.69 & 0.37 \\
\hline 16.38 & 53.66 & 89.27 & 6.45 & 2.32 & 4.13 & 3.78 & 0.35 \\
\hline 21.62 & 93.48 & 91.99 & 8.14 & 2.17 & 5.97 & 5.55 & 0.42 \\
\hline
\end{tabular}

TABLE VI

Distribution OF THE POWER LOSSES AT 10 MHz FOR DiFFERENT OutPut Voltages

\begin{tabular}{|c|c|c|c|c|c|}
\hline $\begin{array}{c}v_{O}[\mathrm{~V}] \\
\left(R_{L}=5 \Omega\right)\end{array}$ & $\begin{array}{c}\text { Total } \\
\text { losses } \\
{[\mathrm{W}]}\end{array}$ & $\begin{array}{c}\text { Driving } \\
\text { losses } \\
{[\%]}\end{array}$ & $\begin{array}{c}\text { Diodes } \\
\text { losses } \\
{[\%]}\end{array}$ & $\begin{array}{c}\text { MOSFETs } \\
\text { losses [\%] }]\end{array}$ & $\begin{array}{c}\text { Other } \\
\text { losses } \\
{[\%]}\end{array}$ \\
\hline 6.11 & 4.16 & 51.33 & 9.56 & 27.97 & 11.14 \\
\hline 9.88 & 4.72 & 46.77 & 12.79 & 33.59 & 6.85 \\
\hline 12.42 & 5.36 & 42.98 & 13.21 & 36.94 & 6.87 \\
\hline 16.38 & 6.45 & 35.92 & 12.72 & 45.91 & 5.45 \\
\hline 21.62 & 8.14 & 26.67 & 7.71 & 60.42 & 5.20 \\
\hline
\end{tabular}

TABLE VII

DETAILS ABOUT THE IMPLEMENTATION OF THE REACTIVE ELEMENTS GIVEN IN TABLE IV

\begin{tabular}{|c|c|c|}
\hline & Design 1 & Design 2 \\
\hline $\mathbf{L}_{1 \mathrm{~A}}=\mathrm{L}_{1 \mathrm{~B}}$ & $\begin{array}{l}-24 \text { turns } \\
\text { - T37-12 toroidal core } \\
\text { - } 24 \text { SWG enameled } \\
\quad \text { wire }(D=0.56 \mathrm{~mm})\end{array}$ & $\begin{array}{l}\text { - } 19 \text { turns } \\
\text { - T37-12 toroidal core } \\
\text { - } 24 \text { SWG enameled } \\
\quad \text { wire }(D=0.56 \mathrm{~mm})\end{array}$ \\
\hline $\mathrm{C}_{2}$ & $2 \times 10 \mathrm{nF}(\mathrm{ATC} 200 \mathrm{~B})$ & $\begin{array}{l}1 \times 10 \mathrm{nF}(\text { ATC 200B) } \\
3 \times 1 \mathrm{nF}(\text { ATC 100B) }\end{array}$ \\
\hline $\mathbf{L}_{3}$ & $\begin{array}{l}\text { - } 17 \text { turns } \\
\text { - T37-12 toroidal core } \\
\text { - } 24 \text { SWG enameled } \\
\quad \text { wire }(D=0.56 \mathrm{~mm})\end{array}$ & $\begin{array}{l}\text { - } 12 \text { turns } \\
\text { - T37-12 toroidal core } \\
\text { - } 22 \text { SWG enameled } \\
\quad \text { wire }(D=0.71 \mathrm{~mm})\end{array}$ \\
\hline $\mathrm{C}_{4}$ & $\begin{array}{l}7 \times 1 \mathrm{nF}(0603 \times 7 R) \\
1 \times 820 \mathrm{pF}(0603 \times 7 R)\end{array}$ & $5 \times 1$ nF $(0603 \times 7 R)$ \\
\hline
\end{tabular}

results obtained in this case are also good, with no appreciable switching-frequency ripple at the output.

Measuring the converter efficiency when it is reproducing envelope waveforms with high bandwidths (2 $\mathrm{MHz}$ in Design 1 and 3.125 MHz in Design 2) is a complex task due to the difficulty of measuring the output power at these frequencies. In the case of the waveform reproduced in Figs. 23(b) and 24(b), it can be easily approximated by a square waveform whose voltage levels are $4.5 \mathrm{~V}$ (low level) and $21.6 \mathrm{~V}$ (high level). According to the efficiency curves given in Fig. 22 and taking into account that the load is a $5-\Omega$ resistor, the output power and the power losses at low level will be 4.5 and $4 \mathrm{~W}$, respectively, whereas the same quantities at a high level will be $93.48 \mathrm{~W}$ and $8.14 \mathrm{~W}$, respectively. Given that the output voltage remains at the low level approximately the same time as in the

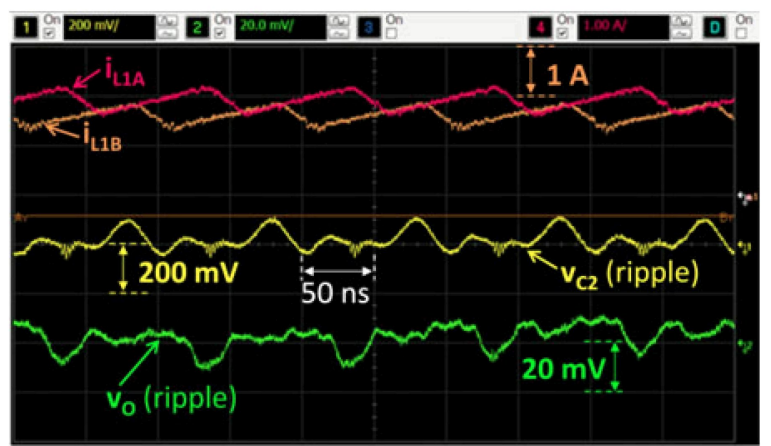

(a)

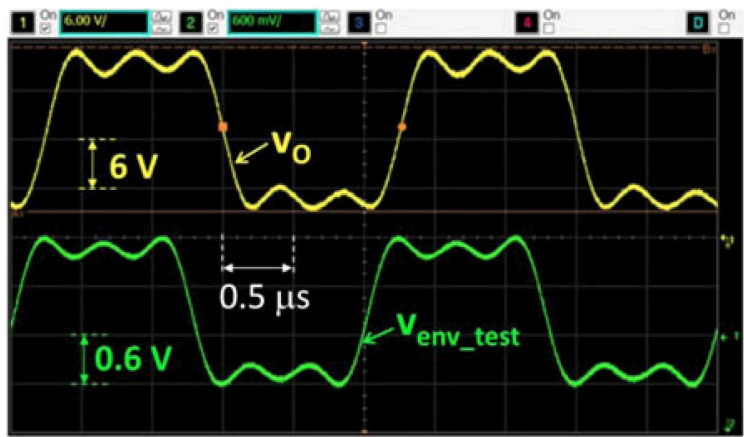

(b)

Fig. 23. Experimental results obtained in the prototype corresponding to Design 1. (a) Waveforms of $i_{L 1 a}$ and $L_{1 B}$ and ripple of $v_{C 2}$ and $v_{O}$. (b) Results with a waveform similar to (19).

high level, the overall efficiency can be calculated by dividing the output power (i.e, $4.5 \mathrm{~W}+93.48 \mathrm{~W}=97.98 \mathrm{~W}$ ) by the addition of this power and the total losses $(97.98 \mathrm{~W}+4 \mathrm{~W}$ $+8.14 \mathrm{~W}=110.12 \mathrm{~W}$ ), the final result being $88.97 \%$. The capability of reproducing high-frequency envelope components (2-3 MHz with the converter switching at $10 \mathrm{MHz}$ ), maintaining high efficiency [above $85 \%$ in the case of the waveforms given in Figs. 23(b) and 24(b)], would be difficult to achieve using the combination of a switching and a linear stage.

The spectra of the voltage across $v_{\mathrm{DA}}$ (which is one of the inputs of the output filter) and of the output voltage are given in Fig. 25 (Design 1) and Fig. 26 (Design 2). The spectrum of $v_{\mathrm{DA}}$ in Design 1 [Fig. 25(a)] shows that envelope frequency components and side bands are far enough to guarantee a little influence of the lower side band over the envelope components. 


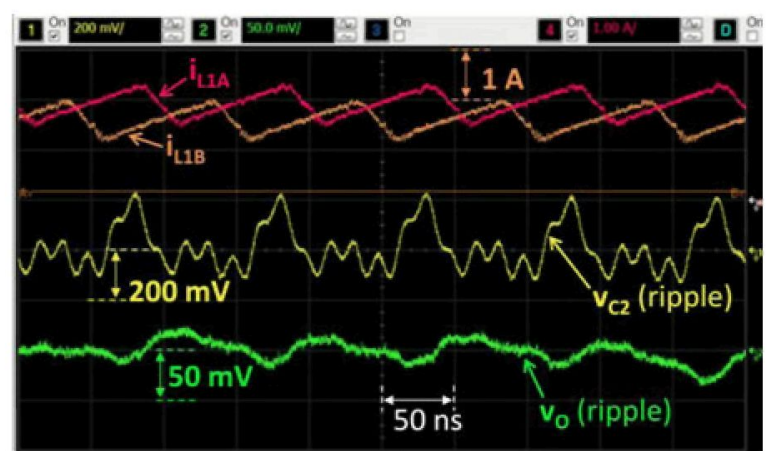

(a)

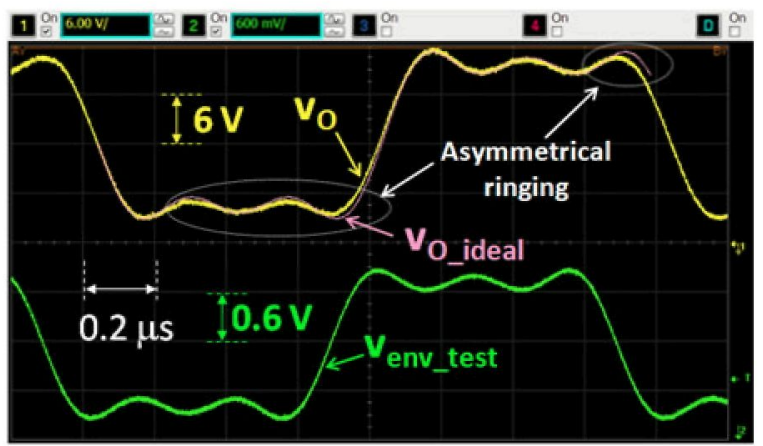

(b)

Fig. 24. Experimental results obtained in the prototype corresponding to Design 2. (a) Waveforms of $i_{L 1 a}$ and $L_{1 B}$ and ripple of $v_{C 2}$ and $v_{O}$. (b) Testing a waveform like the one given in (19).

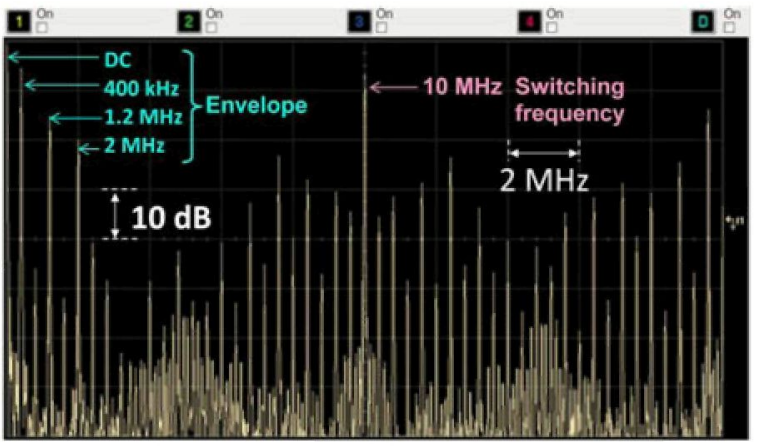

(a)

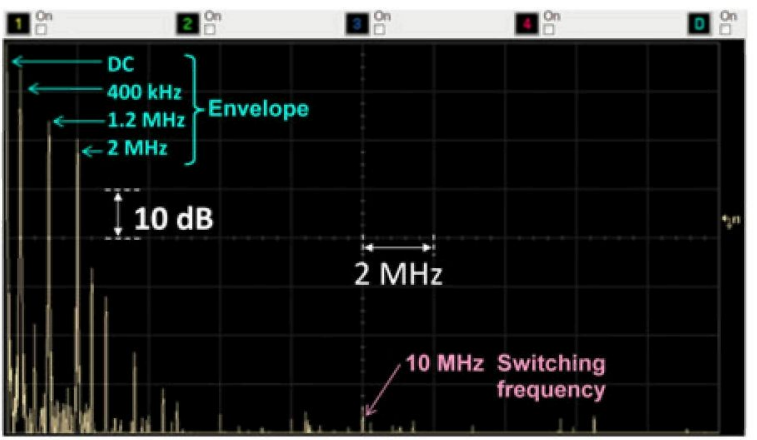

(b)

Fig. 25. For Design 1: (a) spectrum of $v_{\mathrm{DA}}$ and (b) Spectrum of $v_{O}$.

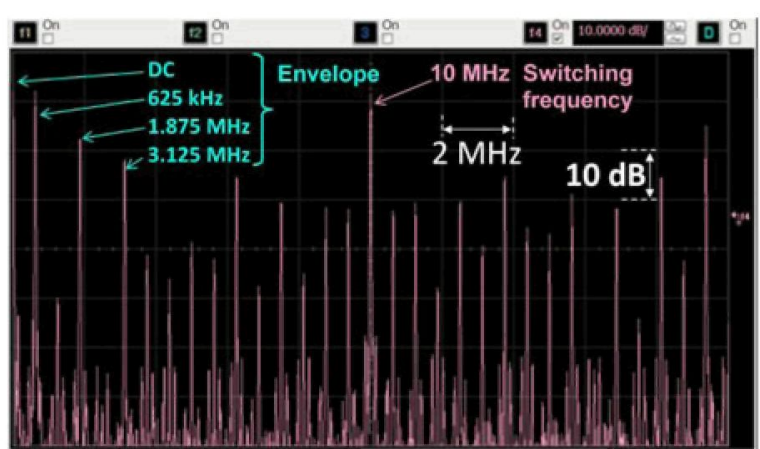

(a)

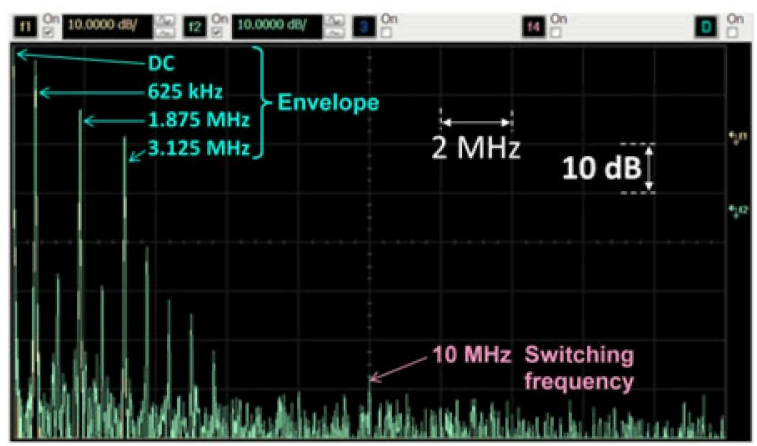

(b)

Fig. 26. For Design 2: (a) spectrum of $v_{\mathrm{D} A}$ and (b) spectrum of $v_{O}$.

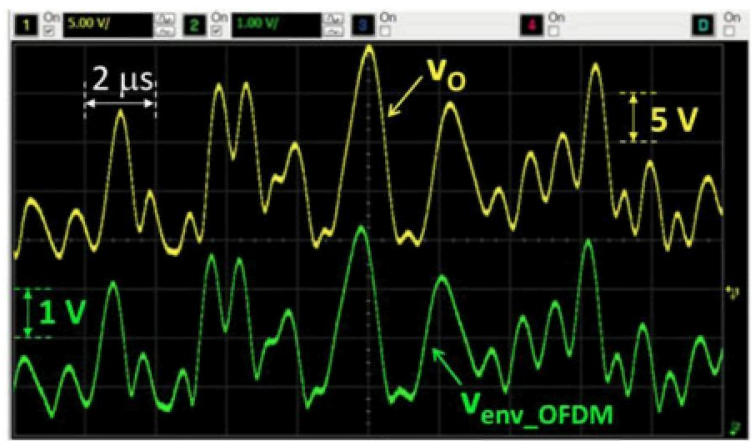

(a)

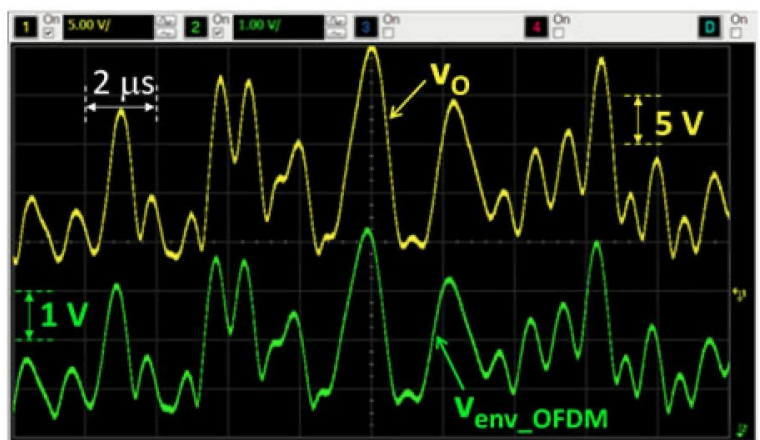

(b)

Fig. 27. Experimental results obtained in the prototypes reproducing the envelope of an OFDM signal with $1.5 \mathrm{MHz}$ of RF bandwidth. a) Design 1. b) Design 2 . 
As a consequence, $v_{O}$ includes very small side-band harmonics [see Fig. 25(b)]. On the other hand, the envelope components and the lower side -band below the switching frequency are closer to the pass band in Design 2 [see Fig. 26(a)], thus causing a slight influence of the lower side band harmonics on the envelope components [see Fig. 26(b)].

The spectra shown in Figs. 25 and 26 allow detecting the notch-filter effect of the two-phase Buck converter. Thus, an attenuation of $38 \mathrm{~dB}$ would be expected in the case of Design 2, excluding the effect of the notch filter (i.e., using this filter in a single-phase converter [33]). However, the attenuation measured comparing the $10 \mathrm{MHz}$ component in Fig. 26(a) and in Fig. 26(b) is clearly higher (about $60 \mathrm{~dB}$ ).

Finally, the prototypes developed have been tested reproducing an actual telecommunication envelope. This envelope corresponds to an OFDM signal with $1.5 \mathrm{MHz}$ of RF bandwidth. The binary data was emulated using pseudorandom bit sequences. The results obtained with both prototypes are given in Fig. 27, where excellent tracking of this signal is clearly appreciated.

\section{CONCLUSION}

A modified two-phase Buck converter using a fourth-order output filter is presented in this paper. This converter has excellent characteristics to be used as an EA in ET or EER applications: it features a linear relationship between duty cycle and output voltage and provides huge rejection of the switching frequency due to the notch filter effect caused by the two-phase operation. It has been shown that the Legendre-Papoulis filter presents the best behavior in the pass band and a strong rejection in the stop band when it is appropriately designed for applications with band-limited envelopes. As the switching frequency component is completely eliminated by the two-phase EA, the ratio between the switching frequency and the highest frequency component in the pass band can be in the range of $3-5$, allowing high efficiency and wide-bandwidth operation. This range strongly depends on the envelope harmonic content, because this content determines the practical lower limit of the lower side band below the switching frequency.

A design procedure based on the attenuation of the lower side band and on the allowed quadratic error of the highest frequency component in the pass band has been proposed and applied to design two 100-W EA switching at $10 \mathrm{MHz}$. Two prototypes using RF Si-LDMOS transistors have been built and tested to demonstrate the feasibility of the proposed topology and design. Efficiencies above $88 \%$ have been obtained, along with very good tracking capabilities demonstrated using test envelope signals with $2 \mathrm{MHz}$ and $3.125 \mathrm{MHz}$ of envelope bandwidth. Moreover, excellent tracking capabilities have also been demonstrated using an OFDM envelope signal with $1.5 \mathrm{MHz}$ of RF bandwidth.

\section{REFERENCES}

[1] G. Hanington, P. F. Chen, P. M. Asbeck, and L. E. Larson, "Highefficiency power amplifier using dynamic power-supply voltage for CDMA applications," IEEE Trans. Microw. Theory Techn., vol. 47, no. 8, pp. 1471-1476, Aug. 1999.
[2] D. Anderson and W. H. Cantrell, "High-efficiency high-level modulator for use in dynamic envelope tracking CDMA RF power amplifiers," in Proc. IEEE MTT-S Int. Microw. Symp., 2001, vol. 3, pp. 1509-1512.

[3] B. Sahu and G. Rincón-Mora, "System-level requirements of DC-DC converters for dynamic power supplies of power amplifiers," in Proc. IEEE Asia-Pacific Conf., 2002, pp. 149-152.

[4] B. Sahu and G. Rincón-Mora, "A high-efficiency linear RF power amplifier with a power-tracking dynamically adaptive Buck-Boost supply," IEEE Trans. Microw. Theory Tech., vol. 52, no. 1, pp. 112-120, Jan. 2004.

[5] A. Soto, J. A. Oliver, J. A. Cobos, J. Cezón, and F. Arévalo, "Power supply for a radio transmitter with modulated supply voltage," in Proc. IEEE Appl. Power Electron. Conf., 2004, vol. 1, pp. 392-398.

[6] N. Wang, V. Yousefzadeh, D. Maksimovic, S. Pajic, and Z. Popovic, "60\% efficient 10-GHz power amplifier with dynamic drain bias control," IEEE Trans. Microw. Theory Tech., vol. 52, no. 3, pp. 1077-1081, Mar. 2004.

[7] F. Wang, A. H. Yang, D. Kimball, L. Larson, and P. Asbeck, "Design of wide-bandwidth envelope-tracking power amplifiers for OFDM applications," IEEE Trans. Microw. Theory Tech., vol. 53, no. 4, pp. 1244-1255, Apr. 2005.

[8] M. C. W. Høyerby and M. A. E. Andersen, "High-bandwidth, highefficiency envelope tracking power supply for $40 \mathrm{~W}$ RF power amplifier using paralleled bandpass current sources," in Proc. IEEE Power Electron. Spec. Conf., 2005, pp. 2804-2809.

[9] V. Yousefzadeh, E. Alarcón, and D. Maksimovic, "Three-level buck converter for envelope tracking applications," IEEE Trans. Power Electron., vol. 21, no. 2, pp. 549-552, Mar. 2006.

[10] D. F. Kimball, J. Jeong, C. Hsia, P. Draxler, S. Lanfranco, W. Nagy, K. Linthicum, L. E. Larson, and P. M. Asbeck, "High-efficiency envelopetracking W-CDMA base-station amplifier using GaN HFETs," IEEE Trans. Microw. Theory Tech., vol. 54, no. 11, pp. 3848-38561, Nov. 2006.

[11] M. C. W. Høyerby and M. A. E. Andersen, "Ultrafast tracking power supply with fourth-order output filter and fixed-frequency hysteretic control," IEEE Trans. Power Electron., vol. 23, no. 5, pp. 2387-2398, Sep. 2008.

[12] M. Rodríguez, P. Fernández-Miaja, A. Rodríguez, and J. Sebastián, "A multiple-input digitally controlled Buck converter for envelope tracking applications in radiofrequency power amplifiers," IEEE Trans. Power Electron., vol. 25, no. 2, pp. 369-381, Feb. 2010.

[13] M. Vasic, O. García, J. Oliver, P. Alou, D. Díaz, and J. Cobos, "Multilevel power supply for high-efficiency RF amplifiers," IEEE Trans. Power Electron., vol. 25, no. 4, pp. 1078-1089, Apr. 2010.

[14] P. M. Cheng, M. Vasic, O. Garcia, J. A. Oliver, P. Alou, and J. A. Cobos, "Design of envelope amplifier based on interleaved multiphase buck converter with minimum time control for RF application," in Proc. IEEE Energy Convers. Congr. Expo., 2011, pp. 1279-1283.

[15] M. Rodríguez, P. Fernández-Miaja, J. Sebastián, and D. Maksimovic, "Mismatch-error shaping-based digital multiphase modulator," IEEE Trans. Power Electron., vol. 27, no. 4, pp. 2055-2066, Apr. 2012.

[16] P. Fernández-Miaja, M. Rodríguez, A. Rodríguez, and J. Sebastián, "A linear assisted DCDC converter for envelope tracking and envelope elimination and restoration applications," IEEE Trans. Power Electron., vol. 27, no. 7, pp. 3302-3309, Jul. 2012

[17] M. C. González, M. Vasic, P. Alou, O. García, J. A. Oliver, and J. A. Cobos, "Transformer-coupled converter for voltage modulation techniques," IEEE Trans. Power Electron., vol. 28, no. 5, pp. 2330-2342, May 2013.

[18] P. Fernández-Miaja, J. Sebastián, R. Marante, and J. A. García, "A linear assisted switching envelope amplifier for a UHF polar transmitter," IEEE Trans. Power Electron., vol. 29, no. 4, pp. 1850-1861, Apr. 2014.

[19] O. García, M. Vasic, P. Alou, J. Oliver, and J. A. Cobos, "An overview of fast DC-DC converters for envelope amplifier in RF transmitters," IEEE Trans. Power Electron., vol. 28, no. 10, pp. 4712-4722, Oct. 2013.

[20] H. Huang, J. Bao, and L. Zhang, "A MASH-controlled multilevel power converter for high-efficiency RF transmitters," IEEE Trans. Power Electron., vol. 26, no. 4, pp. 1205-1214, Apr. 2012.

[21] G. Gong, H. Ertl, and J. W. Kolar, "Novel tracking power supply for linear power amplifier," IEEE Trans. Ind. Electron., vol. 55, no. 2, pp. 684-698, Feb. 2008.

[22] G. Gong, D. Hassler, and J. W. Kolar, "A comparative study of multicell amplifiers for AC-power-source applications," IEEE Trans. Power Electron., vol. 26, no. 1, pp. 149-164, Jan. 2011.

[23] S. Cuk and R. D. Middlebrook, "A general unified approach to modelling switching dc-to-dc converters in discontinuous conduction mode," in Proc. IEEE Power Electron. Spec. Conf., 1977, pp. 36-57.

[24] L. R. Kahn, "Single-sideband transmission by envelope elimination and restoration," in Proc. Inst. Radio Eng., Jul. 1952, pp. 803-806. 
[25] F. H. Raab, B. E. Sigmon, R. G. Myers, and R. M. Jackson, "L-Band transmitter using Kahn EER technique," IEEE Trans. Microw. Theory Tech., vol. 46, no. 12, pp. 2220-2225, Dec. 1998.

[26] D. Milosevic, J. van der Tang, and A. van Roermund, "Intermodulation products in the EER technique applied to Class-E amplifiers," in Proc. IEEE Int. Symp. Circuits Syst., 2004, pp. 637-640.

[27] N. Wang, X. Peng, V. Yousefzadeh, D. Maksimovic, S. Pajic, and Z. Popovic, "Linearity of X-band Class-E power amplifiers in EER operation," IEEE Trans. Microw. Theory Tech., vol. 53, no. 3, pp. 1096-1102, Mar. 2005.

[28] V. Yousefzadeh, N. Wang, Z. Popovic, and D. Maksimovic, "A digitally controlled DC/DC converter for an RF power amplifier," IEEE Trans. Power Electron., vol. 21, no. 1, pp. 64-172, Jan. 2006.

[29] F. Wang, D. F. Kimball, J. D. Popp, A. H. Yang, D. Y. Lie, P. M. Asbeck, and L. E. Larson, "An improved power-added efficiency 19-dBm hybrid envelope elimination and restoration power amplifier for $802.11 \mathrm{~g}$ WLAN applications," IEEE Trans. Microw. Theory Tech., vol. 54, no. 12, pp. 4086-4099, Dec. 2006.

[30] M. Bathily, B. Allard, F. Hasbani, V. Pinon, and J. Verdier, "Design flow for high-switching-frequency and large-bandwidth analog DC/DC stepdown converters for a polar transmitter," IEEE Trans. Power Electron., vol. 27, no. 2, pp. 838-847, Feb. 2012.

[31] H. Peng, V. Pala, P. Wright, T. P. Chow, and M. M. Hella, "High efficiency, high switching speed, AlGaAs/GaAs P-HEMT DC-DC converter for integrated power amplifier modules," J. Analog Integr. Circuits Signal Proc., vol. 66, pp. 331-348, Mar. 2011.

[32] A. García-Tormo, A. Poveda, E. Alarcón, and F. Guinjoan, "Designoriented characterisation of adaptive asynchronous $\Sigma \Delta$ modulation switching power amplifiers for bandlimited signals," in Proc. IEEE Int. Symp. Cincuits Syst., 2009, pp. 2882-2885.

[33] J. Sebastián, P. Fernández-Miaja, A. Rodríguez, and M. Rodríguez, "Analysis and design of the output filter for buck envelope amplifiers," IEEE Trans. Power Electron., vol. 29, no. 1, pp. 213-233, Jan. 2004.

[34] J. G. Proakis and D. G. Manolakis, Digital Signal Processing. Principles, Algorithms and Applications. Englewood Cliffs, NJ: Prentice-Hall, 1996.

[35] R. Schaumann, M. S. Ghausi, and K. R. Laker, Design of Analog Filters. Englewood Cliffs, NJ, USA: Prentice-Hall, 1990.

[36] W. J. Kerwin, Electrical Engineering Handbook. Chapter 4: Passive Signal Processing. Boca Raton, FL, USA: CRC Press, 1993.

[37] E. C. Jones, H. W. Hale, A. B. Williams, and F. J. Taylor, Electronics Engineers' Handbook. Chapter 16: Filters and Attenuators. New York, NY, USA: McGraw-Hill, 1996.

[38] D. G. Holmes and T. A. Lipo, Pulse Width Modulation for Power Converters: Principles and Practice. New York, NY, USA: Wiley, 2003.

[39] L. Marco, A. Poveda, E. Alarcón, and D. Maksimovic, "Bandwidth limits in PWM switching amplifiers," in Proc. IEEE Int. Symp. Circuits Syst., 2006, pp. 5323-5326.

[40] F. F. Kuo, Network Analysis and Synthesis. New York, NY, USA: Wiley, 1966.

[41] G. C. Temes and J. W. LaPatra, Introduction to circuit synthesis and design. New York, NY, USA: McGraw-Hill, 1977. 